Computational Physics and Engineering Division (10)

Contract Program or Project Title:

Subject of this Document:

Type of Document:

Authors:

Date Published:

Responsible NRC Individual and NRC Office or Division:
Development and Application of Criticality Safety Software for Licensing Review

Production of Probability Tables for the UnresolvedResonance Region Using the AMPX Cross-section Processing System

\section{Letter Report}

M. E. Dunn

October 2000

D. D. Ebert (301) 415-6501

U.S. Nuclear Regulatory Commission

Prepared for the

U.S. Nuclear Regulatory Commission

Washington, D.C. 20555-0001

under Interagency Agreement DOE 1886-C647-9W

NRC JCN No. W6479

Prepared by the

OAK RIDGE NATIONAL LABORATORY

P.O. Box 2008

Oak Ridge, Tennessee 37831-6370

managed and operated by

UT-Battelle, LLC

for the

U.S. DEPARTMENT OF ENERGY

under Contract No. DE-AC05-00OR22725 



\title{
Production of Probability Tables for the Unresolved-Resonance Region Using the AMPX Cross-section Processing System
}

\author{
M. E. Dunn \\ Oak Ridge National Laboratory \\ P.O. Box 2008 \\ Oak Ridge, TN 37831-6370
}

Manuscript Completed: October 2000

Date Published: October 2000

\author{
Prepared for the \\ U.S. Nuclear Regulatory Commission \\ Washington, D.C. 20555-0001 \\ under Interagency Agreement DOE 1886-C647-9W \\ NRC JCN No. W6479
}

Prepared by the

OAK RIDGE NATIONAL LABORATORY

P.O. Box 2008

Oak Ridge, Tennessee 37831-6370

managed and operated by

UT-Battelle, LLC

for the

U.S. DEPARTMENT OF ENERGY

under Contract No. DE-AC05-00OR22725 



\section{CONTENTS}

Page

LIST OF FIGURES $\ldots \ldots \ldots \ldots \ldots \ldots \ldots \ldots \ldots \ldots \ldots \ldots \ldots \ldots \ldots \ldots \ldots$

LIST OF TABLES $\ldots \ldots \ldots \ldots \ldots \ldots \ldots \ldots \ldots \ldots \ldots \ldots \ldots \ldots \ldots \ldots \ldots$

ACKNOWLEDGMENTS $\ldots \ldots \ldots \ldots \ldots \ldots \ldots \ldots \ldots \ldots \ldots \ldots \ldots \ldots \ldots \ldots \ldots$

I. INTRODUCTION $\ldots \ldots \ldots \ldots \ldots \ldots \ldots \ldots \ldots \ldots \ldots \ldots \ldots \ldots \ldots \ldots \ldots \ldots$

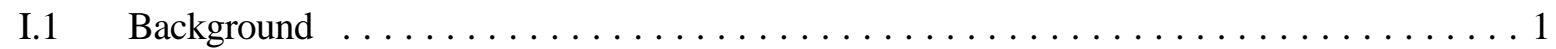

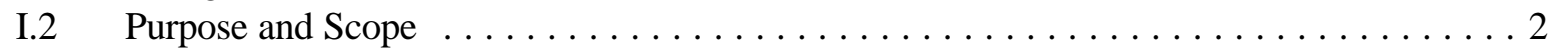

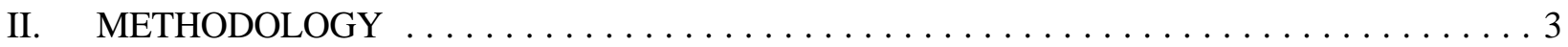

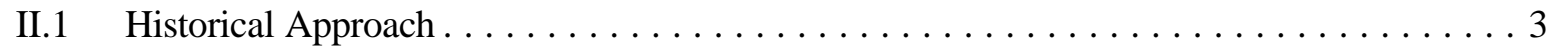

II.2 PURM Calculational Procedure $\ldots \ldots \ldots \ldots \ldots \ldots \ldots \ldots \ldots \ldots \ldots \ldots \ldots$

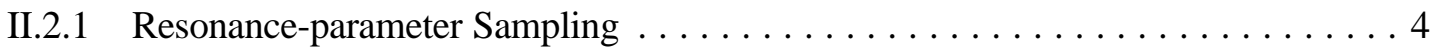

II.2.2 Dyson and Mehta ${ }_{3}{ }_{3}$ Statistics Test $\ldots \ldots \ldots \ldots \ldots \ldots \ldots \ldots \ldots \ldots \ldots \ldots \ldots \ldots$

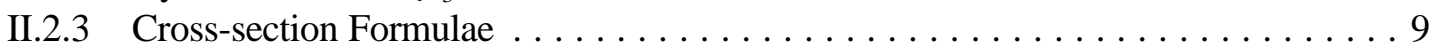

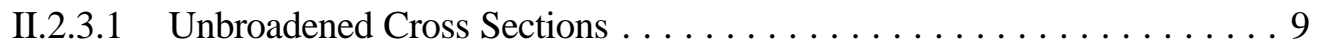

II.2.3.2 Broadened Cross Sections $\ldots \ldots \ldots \ldots \ldots \ldots \ldots \ldots \ldots \ldots \ldots$

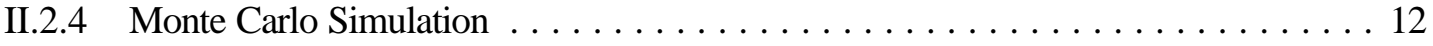

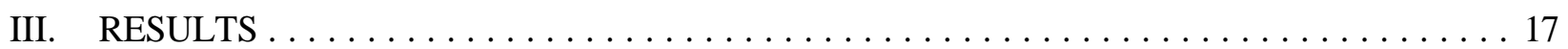

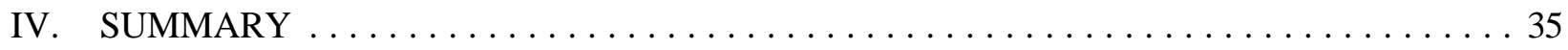

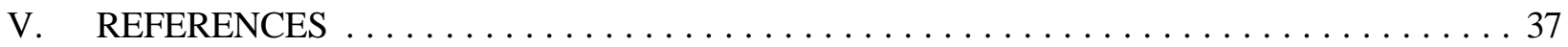




\section{LIST OF FIGURES}

Figure $\quad$ Page

III.1. Calculated average total cross section by batches run $\ldots \ldots \ldots \ldots \ldots \ldots \ldots \ldots \ldots$

III.2. Calculated average total cross section by batches skipped $\ldots \ldots \ldots \ldots \ldots \ldots \ldots$

III.3. Frequency distribution for ${ }^{235} \mathrm{U}$ total cross-section calculation at $2.25 \mathrm{keV} \ldots \ldots \ldots \ldots 22$

III.4. Calculated probability table for ${ }^{235} \mathrm{U}$ at $2.25 \mathrm{keV} \ldots \ldots \ldots \ldots \ldots \ldots \ldots \ldots \ldots$

III.5. Calculated probabilities as a function of cross-section band for ${ }^{235} \mathrm{U}$ at $2.25 \mathrm{keV} \ldots \ldots . .24$

III.6. Calculated total cross section as a function of cross-section band for ${ }^{235} \mathrm{U}$ at $2.25 \mathrm{keV} \ldots \ldots 25$

III.7. Calculated capture cross section as a function of cross-section band for ${ }^{235} \mathrm{U}$ at $2.25 \mathrm{keV}$. . 26

III.8. Calculated fission cross section as a function of cross-section band for ${ }^{235} \mathrm{U}$ at $2.25 \mathrm{keV}$. . 27

III.9. Calculated scatter cross section as a function of cross-section band for ${ }^{235} \mathrm{U}$ at $2.25 \mathrm{keV} \ldots 28$

III.10. Probability-table comparison between PURM and NJOY for ${ }^{235} \mathrm{U}$ at $2.25 \mathrm{keV} \ldots \ldots \ldots 30$

III.11. Total cross-section comparison between PURM and NJOY for ${ }^{235} \mathrm{U}$ at $2.25 \mathrm{keV} \ldots \ldots . .31$

III.12. Capture cross-section comparison between PURM and NJOY for ${ }^{235} \mathrm{U}$ at $2.25 \mathrm{keV} \ldots \ldots 32$

III.13. Fission cross-section comparison between PURM and NJOY for ${ }^{235} \mathrm{U}$ at $2.25 \mathrm{keV} . \ldots . . .33$

III.14. Scatter cross-section comparison between PURM and NJOY for ${ }^{235} \mathrm{U}$ at $2.25 \mathrm{keV} \ldots \ldots . . .34$ 


\section{LIST OF TABLES}

Table $\quad$ Page

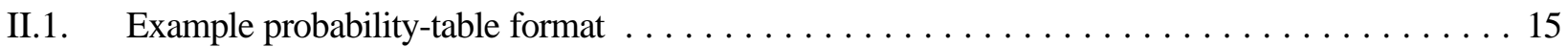

III.1 Calculated ${ }^{235} \mathrm{U}(\mathrm{ENDF} / \mathrm{B}-\mathrm{VI})$ average cross-section values in the unresolved-resonance

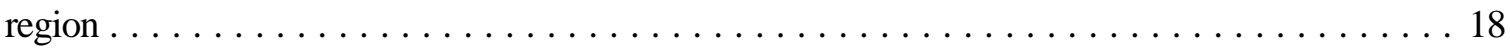




\section{ACKNOWLEDGMENTS}

Special appreciation is expressed to D.D. Ebert and D. E. Carlson of the Nuclear Regulatory Commission for their support of this effort. Appreciation is also expressed to L. C. Leal who is the author of the URR code that served as the basis for this work. 


\section{INTRODUCTION}

\section{I.1 Background}

The tasks associated with the "Development and Applicability of Criticality Safety Software for Licensing Review" are documented in the DOE Laboratory Project and Cost Proposal for NRC Work (JCN W6479). ${ }^{1}$ Six tasks are documented that address the upgrade to the AMPX code system. ${ }^{2}$

The AMPX upgrade is intended to facilitate independent ${ }^{\mathrm{H}}$ processing of Version VI formats of the Evaluated Nuclear Data File (ENDF) using state-of-the-art procedures. Consequently, a comprehensive and alternative processing capability would be available to generate neutron cross-section data for criticality safety licensing applications. Task 8 of the cost proposal addresses the development of the capability to generate probability tables for treating resonance data. To date, a substantial amount of code development is complete, and in accordance with the reporting requirements for Task 8 of the cost proposal, this letter report documents the capabilities for generating probability-table data for neutron transport applications.

For resonance isotopes, the resonance region is typically divided into a resolved- and unresolved-resonance region (i.e., RRR and URR, respectively). The boundaries of the different energy ranges are extremely material dependent. The RRR is an energy region that is characterized by well-defined resonances. In other words, the experimental resolution is sufficient to permit the determination of the resolved-resonance parameters by area or shape analysis. In the RRR, cross-section functions can be generated as continuous or pointwise functions with respect to energy.

In contrast to the RRR, the URR is an energy region in which the experimental resolution is inadequate for determining the resonance parameters of individual resonances. As a result, the unresolved-resonance parameters are averages of resolved-resonance parameters over specific energy intervals; however, the values of the parameters vary as a function of the different energy intervals. As a result, the conventional approach for the URR is to calculate effective or average cross sections at an energy point within a specified energy-averaging interval. Consequently, the energy-dependent cross sections have a relatively smooth structure in the URR relative to the RRR. The smooth structure in the URR is nonphysical because the resonance structure can extend into the URR.

Due to the statistical nature of the unresolved-resonance parameters, probability tables can be used to provide cross-section probability distribution functions for energy ranges at specific temperatures within the URR. In particular, the tables provide a distribution of cross-section values and corresponding probabilities for a specified energy range within the URR. During a continuous-energy Monte Carlo neutron transport calculation, the requiste cross-section values can be sampled from the probability distribution at the neutron energy during the random walk. As a result, the self-shielding effects within the URR can arise naturally during the random walk, and the resulting Monte Carlo simulation is more analogus to the actual particle transport relative to using the effective or average cross-section value.

\footnotetext{
Currently, NJOY ${ }^{3}$ is the only production-level code system that has the capability to process ENDF/B-VI crosssection evaluations.
} 


\section{I.2 Purpose and Scope}

Although probability tables can be generated for both the resolved- and unresolved-resonance regions, this work focuses on the calculation of probability tables for the unresolved region. Prior to this work, the capability for generating probability tables was not available in AMPX. In an effort to satisfy the objective of Task 8 under JCN W6479, a new module, PURM (Probability tables for the $\underline{\text { Unesolved }}$ Region using Monte Carlo), has been developed for the AMPX cross-section processing system. As implied by the name of the new module, a Monte Carlo approach is used to calculate probability tables for the URR, and a descriptive overview of the methodology is presented in Section II of this letter report. The purpose of this letter report is to document the capability for producing probability tables in the URR. In order to demonstrate the computational capability for this work, the probability tables that are generated with PURM are compared with probability tables that are calculated using NJOY. Comparisons with NJOY are sufficient to establish the computational capability for generating probability tables using the AMPX code system.

Note that the objective of Task 10 under JCN W6479 is to demonstrate the capability for AMPX to produce continuous-energy neutron cross-section data for use with MCNP. ${ }^{4}$ Since MCNP has the capability to utilize probability tables in the unresolved region, the completion of Task 8 provides the foundation for implementation of the probability-table method in a continuous-energy Monte Carlo code such as MCNP. Furthermore, future testing associated with Task 10 will demonstrate the implementation of probability tables in MCNP and provide a mechanism for testing the probability tables in criticality safety benchmark calculations. 


\section{METHODOLOGY}

The objective of the probability-table method is to calculate a distribution function for the cross-section values in a specific energy range within the unresolved-resonance region (URR). The approach is in direct contrast with the procedures of the resolved-resonance region (RRR) in which the neutron cross section is obtained at a specific energy using the appropriate resonance formula. The cross-section distribution function is characterized by having a mean value that is equivalent to the infinite-dilution cross-section value for the energy range of interest.

Since other methods exist for the calculation of probability tables, a brief description of the most common or conventional approach is presented prior to describing the procedures that are used by PURM. Following the brief review of the conventional approach for calculating probability tables is a description of the procedures used by PURM to calculate probability tables in the URR.

\section{II.1 Historical Approach}

Different approaches can be used to generate probability tables for the isotope/nuclide of interest. The conventional or historical approach is to generate continuous-energy cross-section data from a "ladder" of resonances and determine contributions to a probability table based on the point data. This process is then repeated over additional ladders of resonances until the desired number of ladders is processed. The ladder approach, which is described by Levitt, ${ }^{5}$ is the basis for the probability-table method in NJOY. ${ }^{3}$ For the energy range of interest in the URR, a random energy grid is generated over the desired energy range. Subsequently, a ladder of resonances is generated over the energy range, and the spacing distribution of the resonances is sampled according to a Wigner spacing distribution. In order to complete the specifications for each resonance, the resonance widths are sampled according to a Chi-square distribution. Once the energy grid and set of resonance parameters are determined, cross sections are calculated at each grid point by summing over the resonances for each spin sequence. For the URR, the single-level Breit-Wigner (SLBW) resonance formalism is used to calculate the cross-sections in the unresolved range. The calculated crosssection values are accumulated into a probability table, and the mean cross-section value is obtained by averaging over the calculated cross-section values in the energy range of interest. After completing the calculation for one ladder of resonances, another ladder of resonances is generated, and the cross sections are calculated on the random energy grid. The process is repeated over as many ladders as specified by the user. 


\section{II.2 PURM Calculational Procedure}

\section{II.2.1 Resonance-parameter Sampling}

A slightly different procedure relative to the "ladder" approach is used in the new module PURM. PURM uses a Monte Carlo procedure to calculate probability tables on the evaluator-defined energy grid in the URR. The Monte Carlo procedure used in PURM is based on the methodology in the code $\mathrm{URR}^{6}$ that was developed at the Oak Ridge National Laboratory in the late 1980s. As opposed to generating a ladder of resonances, PURM determines pairs of resonances surrounding the reference energy or energies for each table. As in the ladder approach, the resonance spacings are sampled from a Wigner spacing distribution:

$$
f(x){ }^{\prime} W(x)^{\prime}, \frac{\mathrm{B}}{2} x e^{\& \frac{\mathrm{B}}{4} x^{2}},
$$

where

$$
x^{\prime} \frac{D_{\mathrm{R} J}}{\left\langle D_{\mathrm{R} J}\right\rangle},
$$

and

$$
\begin{array}{ll}
\mathrm{R} & =\text { relative neutron-nucleus angular momentum, } \\
J & =\text { spin of the resonance, } \\
D_{\mathrm{R},} & =\text { resonance spacing corresponding to Rand } J, \\
\left\langle D_{\mathrm{R}, J}\right\rangle & =\text { mean spacing of the } D_{\mathrm{R},} \text { level series that is provided in the ENDF data. }
\end{array}
$$

The spacing distribution in Equation (2.1) is a probability density function (PDF) that has the following property:

$$
\mathrm{m}_{0}^{4} f(x) d x^{\prime} 1 .
$$

In order to sample Equation (2.1) for the resonance spacing (i.e., $D_{\mathrm{R}, J}$ ), the PDF is converted to a cummulative distribution function (CDF) by integrating Equation (2.1) from 0 to $x$. As a result, the following CDF is obtained for sampling the resonance spacing:

$$
F(x)^{\prime} \quad 1 \& e^{\& \frac{\mathrm{B}}{4} x^{2}} .
$$


A value for $x$ is obtained by setting $F(x)$ equal to a random number between 0 and 1 . Once a value for $x$ is obtained, the resonance spacing can be calculated based on Equation (2.2).

Once the spacing is sampled from the Wigner distribution, the position of the reference energy in the spacing is selected from a uniform distribution:

$$
p(x \mathbb{N})^{\prime} \frac{1}{D_{\mathrm{R} J}} .
$$

After converting the PDF in Equation (2.5) to a CDF, the following expression is obtained for the position of the reference energy in the spacing distribution:

$$
x \mathrm{~N}^{\prime} \quad R D_{\mathrm{R} J} .
$$

In Equation (2.6), $R$ is a random number, and the positions of the first and second resonances relative to the reference energy, $E_{0}$, are obtained by the following expressions:

$$
E_{8}{ }^{\prime}{ }^{\prime} E_{0} \% x \mathrm{~N},
$$

and

$$
E_{8^{\prime} 2}{ }^{\prime} E_{0} \% x \mathrm{~N} \& D_{\mathrm{R} J} .
$$

As noted previously, the first pair of resonances that are located above and below the reference energy are determined by Equations (2.7) and (2.8). For the remaining pairs of resonances to be processed, the resonance spacings are sampled from the Wigner distribution, and the location of the resonances are determined using a procedure that is analogous to the steps for the first pair of resonances. Although the procedure for sampling the resonance spacing is straightforward, the code must determine the appropriate number of pairs of resonances to sample. In an effort to estimate the number of resonances to sample, PURM uses the ) ${ }_{3}$-statistics test which is described in Section II.2.2.

Once the distribution of energy levels is sampled, the resonance widths must be sampled for each resonance. In the unresolved region, the ENDF data provide average widths for reference energies in the URR. The distribution function for the resonance widths follow a Chi-square (i.e., $\mathrm{P}^{2}$ ) distribution with a designated number of degrees of freedom:

$$
P_{<}(y) \cdot \frac{<}{2 G(\varangle 2)}(<y / 2)^{\frac{\leq}{2} \& 1} e^{\varepsilon<y / 2},
$$


where

$$
y^{\prime} \frac{18 c}{\left\langle{ }^{\prime} 8 c\right.},
$$

and

$$
\begin{array}{lll}
c & = & \text { type of width (e.g., } f \text {-fission, } n \text {-neutron, etc.) }, \\
{ }^{1} 8 c & = & \text { resonance width for energy level } 8, \\
\left.{ }^{\prime} 8 c\right\rangle & = & \text { average width for a given energy range, } \\
\langle & = & \text { number of degrees of freedom, } \\
\mathrm{G}(\varangle 2)= & \text { mathematical gamma function. }
\end{array}
$$

For the neutron width, <is typically equal to 1, and Equation (2.9) has the form of the Porter-Thomas distribution law of the neutron width. ${ }^{8,9}$ Fission is regarded as a few-channel process, and two or three degrees of freedom ( $<=2$ or 3 ) are typically assumed for the fission width distribution. Regarding neutron capture, there are a large number of capture channels that are available, and the number of degrees of freedom is assumed to approach infinity $(<64)$, and the $\mathrm{P}^{2}$-distribution becomes a Dirac-delta function centered at ${ }^{\prime}{ }_{8}=\langle '\rangle$. As noted previously, the ENDF data provide the average resonance widths along with the number of degrees of freedom for the corresponding $\mathrm{P}^{2}$-distribution. During the Monte Carlo simulation, PURM obtains the widths for each resonance by sampling the $\mathrm{P}^{2}$-distribution with the corresponding number of degrees of freedom.

\section{II.2.2 Dyson and Mehta ) ${ }_{3}$-Statistics Test}

One of the essential tasks for constructing the resonance distribution for a given spin sequence (i.e., R $J$ pair) is the determination of the appropriate number of pairs of resonances to process. A useful tool for evaluating the distribution of resonances is the ${ }_{3}$-statistics test that was developed by Dyson and Mehta. ${ }^{7,8}$ PURM uses the $)_{3}$ test to determine the appropriate number of pairs of resonances to process for each spin sequence. Prior to describing the implementation of the ) ${ }_{3}$ test in PURM, the methodology for the $)_{3}$ test is presented in the subsequent discussion.

The $)_{3}$ test provides a measure of the mean-square deviation between the number of observed energy levels (i.e., resonances) within an energy interval from $E_{i}$ to $E_{f}$. The definition for the $)_{3}$ statistics is given by the following expression: ${ }^{8}$

$$
)_{3} \cdot \operatorname{Min}(a, b)\left[\frac{1}{2 L}{\underset{E}{E_{i}}}^{E_{f}}(N(E) \& a E \& b)^{2} d E\right],
$$

where

$$
2 L=\quad \text { the total number of resonances, }
$$




$$
\begin{array}{lll}
N(E)= & \text { the observed cumulative number of resonances as a function of energy. } \\
a & = & \text { the slope for a linear fit to the observed cumulative number of resonances } \\
b & = & \begin{array}{l}
\text { as a function of energy. } \\
\text { the constant for a linear fit to the observed cumulative number of } \\
\text { resonances as a function of energy. }
\end{array}
\end{array}
$$

The procedures for calculating $a$ and $b$ are provided in the following discussion. A numerical representation for Equation (2.11) is presented in Ref. 8 and is provided by the following equation:

$$
)_{3}{ }^{\prime} \frac{1}{E_{f} \& E_{i}}\left[{ }_{8}^{\mathrm{j} / L} \mid 8^{2}\left(E_{8 \%} \& E_{8}\right)\right] \&\left({ }_{1} a \&\left({ }_{2} b\right],\right.
$$

where

$$
\begin{array}{lll}
8 & = & \text { the index for the number of resonances, } \\
E_{8} & = & \text { resonance energy corresponding to index 8, } \\
-L & = & \text { the first resonance in the series, } \\
+L & = & \text { the last resonance in the series. }
\end{array}
$$

In Equation (2.12), the quantities $\left(_{1}\right.$ and $\left(_{2}\right.$ are defined as follows:

$$
\left(l_{1}, \frac{1}{2} \mathrm{j}_{8} \quad 8\left(E_{8 \%}^{2} \& E_{8}^{2}\right),\right.
$$

and

$$
\left({ }_{2}{ }^{\prime} \mathrm{j}_{8} 8\left(E_{8 \%} \& E_{8}\right)\right.
$$

As indicated by Equation (2.11), the $)_{3}$ test also provides a linear fit for the cumulative number of levels as a function of energy. The slope and constant for the linear fit are provided by the following equations:

$$
\begin{gathered}
a, \frac{\left(_ { 1 } \& \left(_{2} \$_{1} / \$_{2}\right.\right.}{{ }_{1} \&{ }_{2} \$_{1} / \$_{2}}, \\
b \cdot \frac{l_{2}}{\$_{2}} \& \frac{2}{\$_{2}}\left(\frac{\left(_{1} \&{ }_{2} \$_{1} / \$_{2}\right.}{{ }_{1} \&{ }_{2} \$_{1} / \$_{2}}\right) .
\end{gathered}
$$

The definitions for the variables " ${ }_{1}, "{ }_{2}, \$_{1}$ and $\$_{2}$ are provided by the following expressions: 


$$
\begin{gathered}
{ }_{1}{ }_{1} \frac{1}{3}\left(E_{f}^{3} \& E_{i}^{3}\right), \\
"{ }_{2} \quad \$_{1} \text { ' } \frac{1}{2}\left(E_{f}^{2} \& E_{i}^{2}\right),
\end{gathered}
$$

and

$$
\$_{2}{ }^{\prime} E_{f} \& E_{i}
$$

For each spin sequence, Equation (2.12) can be used to calculate a ) 3 value for the sampled distribution of resonances. The Dyson and Mehta $)_{3}$ test also predicts that the theoretical average value for $)_{3}$ is given by the following expression:

$$
<)_{3}>\frac{1}{\mathrm{~B}^{2}}[\ln (n) \& 0.0687]
$$

where

$$
\mathrm{n}=\quad \text { number of energy levels observed in the interval from } E_{i} \text { to } E_{f} \text {. }
$$

The variance of \langle)$_{3}>$ is given by the following equation:

$$
V_{<)_{3}>}, \frac{1.169}{\mathrm{~B}^{4}}
$$

The objective of the $)_{3}$ test is to determine a resonance spacing distribution that provides a ) 3 value that is in agreement with the theoretical value provided by Equation (2.20). In addition to the comparison between the calculated and theoretical values for $)_{3}$, the linear fit for the cumulative number of levels (i.e., $N(E)=$ $a E+b$ ) should agree with the observed number of levels in the sampled distribution.

Based on experience, there is a two-part convergence problem for the implementation of the ${ }_{3}$-statistics test. One part involves the linear fit for $N(E)$ as a function of energy, and the second part involves the convergence of the ) ${ }_{3}$ values. In other words, reasonable ) ${ }_{3}$ values (i.e., within 2 standard deviations of theoretical value) may be obtained for a sampled distribution; however, the cumulative number of resonances that are predicted by the linear fit may not correspond to the observed number of resonances for the distribution. In contrast, an acceptable linear fit for the cumulative number of resonances may be obtained for a sampled distribution, but the ) 3 value for the sampled distribution may disagree with the theoretical value by more than two standard deviations. The $)_{3}$ test is extremely sensitive to the location of each level in the distribution. As a result, sampling a sufficient number of resonances does not insure that the correct location of each level is obtained in the distribution. 
Regarding implementation of the $)_{3}$ test, PURM determines the number of levels (i.e., pairs of resonances) to sample for each spin state based on a linear fit for the cumulative number of observed levels. In other words, PURM samples a Wigner distribution to obtain a distribution of resonances using some initial value for the pairs of resonances to sample about the reference energy. The linear fit for the cumulative number of levels is compared with the observed number of levels of the sampled distribution. The number of pairs of resonances to sample is incremented until the observed number of levels in the sampled distribution is predicted to within $0.1 \%$ by the linear fit for $N(E)$. The $)_{3}$ value is also calculated for the sampled distribution; however, PURM currently does not attempt to find a resonance distribution that has a ) 3 value within two standard deviations of the theoretical value as well as an acceptable linear fit for the cumulative number of levels. Extensive CPU times would be required to seek convergence for both the ) 3 value and an acceptable fit for the cumulative number of levels. In an effort to reduce computational times, PURM searches for the distribution that provides an acceptable linear fit for the cumulative number of levels. Based on calculational experience, accurate cross-section values can be obtained by seeking convergence for the cumulative number of levels. Note that the partial implementation of the $)_{3}$-statistics test provides a substantial improvement for the resonance spacing sampling procedure in PURM.

\section{II.2.3 Cross-section Formulae}

Sections II.2.1 and II.2.2 provide an overview of the procedures for sampling the resonance spacings and corresponding resonance widths in the unresolved region. The sampled widths and spacings are used to calculate cross sections in the URR using the single-level Breit-Wigner (SLBW) formula. PURM has the capability to calculate unbroadened cross sections (i.e., $0 \mathrm{~K}$ ) as well as temperature-dependent cross sections in the unresolved region. Using the sampling procedures from Section II.2.2, resonance parameters can be obtained for individual resonances. Subsequently, the sampled resonance parameters can be used to calculate temperature-dependent cross sections. The following two sections provide the appropriate formula for calculating cross sections from the resonance sampled parameters.

\section{II.2.3.1 Unbroadened Cross Sections}

Regarding the unbroadened cross sections, the scattering cross section at energy $E$ is calculated with the following expression:

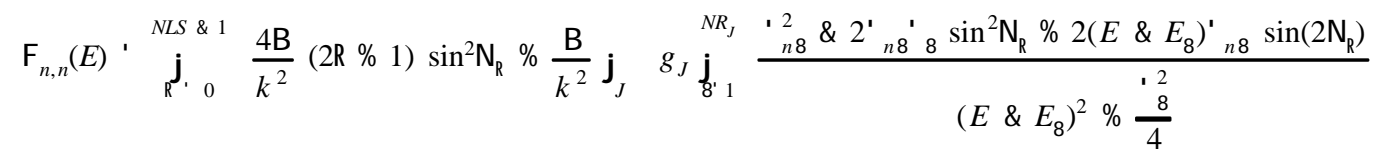

where

$\begin{array}{lll}\mathrm{R} & = & \text { relative neutron-nucleus angular momentum, } \\ N L S & = & \text { total number of Rstates, } \\ k & = & \text { neutron wave number at energy } E, \\ \mathrm{~N}_{\mathrm{R}}= & \text { angular momentum hard sphere phase shift at energy } E, \\ J & = & \text { spin of the resonance, } \\ g_{J} & = & \text { statistical spin factor, }\end{array}$




$$
\begin{array}{lll}
8 & = & \text { resonance index, } \\
N R_{J} & = & \text { number of resonances with spin } J, \\
1 n 8 & = & \text { neutron line width at energy } E, \\
8 & = & \text { total resonance width at energy } E, \\
E_{8} & = & \text { resonance energy. }
\end{array}
$$

Expressions for the hard sphere phase shift are provided in Ref. 10.

The statistical spin factor, $g_{J}$, for neutrons is given by the following equation:

$$
g_{J} \cdot \frac{(2 J \% 1)}{2(2 I \% 1)}
$$

where

$$
I \quad=\quad \text { spin of the target nucleus. }
$$

The neutron wave number, $k$, in Equation (2.21) is implicitly denoted as a function of energy and is calculated with the following relation:

$$
k^{\prime} \quad 2.196771 \times 10^{\& 3} \frac{A W R I}{A W R I \% 1.0} \sqrt{E},
$$

where

$A W R I=\quad$ ratio of the target isotope mass to the neutron mass,

$E \quad=\quad$ energy in the laboratory system.

Regarding capture and fission, the SLBW representations for capture and fission are provided by the expression:

$$
\mathrm{F}_{n, c}(E){ }_{\mathrm{R}^{\prime} 0}^{N L S \& 1} \frac{\mathrm{B}}{k^{2}} \mathrm{j}_{J} \quad g_{J} \mathrm{j}_{8^{\prime} 1}^{N R_{J}} \frac{{ }_{n 8}{ }_{c 8}}{\left(E \& E_{8}\right)^{2} \% \frac{1}{4}{ }^{\prime}{ }^{2}} .
$$

where

$$
{ }^{1} 8=\text { capture }(c=() \text { or fission }(c=f) \text { width at energy } E \text {. }
$$

The total cross section at $E$ is obtained by summing each of the partial cross sections (i.e., scatter, capture and fission). 


\section{II.2.3.2 Broadened Cross Sections}

Doppler broadening of the cross sections is approximated by averaging the unbroadened cross sections over a Maxwellian distribution of velocities. ${ }^{6}$ The scatter cross section is provided by the formula:

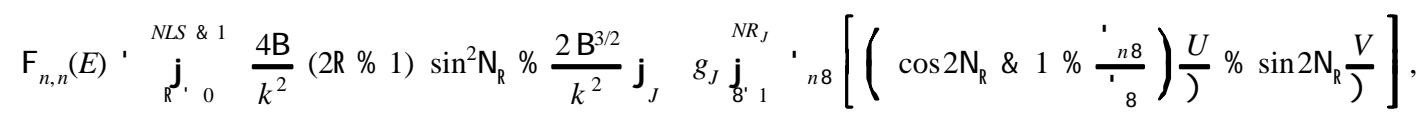

where

$$
\begin{gathered}
)^{\prime}\left(\frac{4 E_{8} k T}{A}\right)^{1 / 2}, \\
U\left(\frac{2 X}{2}, \frac{2}{2}\right), \operatorname{Re} W\left(\frac{2 X}{2}, \frac{2}{2}\right), \\
V\left(\frac{2 X}{2}, \frac{2}{2}\right), \operatorname{Im} W\left(\frac{2 X}{2}, \frac{2}{2}\right),
\end{gathered}
$$

In Equation (2.25), ) is the Doppler width, and $U$ and $V$ are related to the complex probability integral that is defined as follows:

$$
W(x, y)^{\prime} e^{\&(x \% i y)^{2}} \operatorname{erfc}\left[\mathcal{E}_{i}(x \% i y)\right]
$$

Likewise, $U$ and $V$ are related to the symmetric- and antisymmetric-line-shape functions (i.e., $\mathrm{R}$ and $\mathrm{P}$, respectively) as follows:

$$
\mathrm{R}(2, X), \frac{2 \sqrt{\mathrm{B}}}{2} U\left(\frac{2 X}{2}, \frac{2}{2}\right)
$$

and

$$
\mathrm{P}(2, X), \quad 2 \sqrt{\mathrm{B}} V\left(\frac{2 X}{2}, \frac{2}{2}\right) \text {. }
$$

The parameters 2 and $X$ in Equations (2.30) and (2.31) are defined as follows: 


$$
\begin{aligned}
& 2 \cdot \sqrt{\frac{A}{4 k T E_{8}}}{ }_{8}, \\
& X \cdot \frac{2\left(E \& E_{8}\right)}{{ }_{8}} .
\end{aligned}
$$

The capture and fission cross section as a function of temperature are provided by the following equation:

$$
\mathrm{F}_{n, c}(E) \cdot \frac{2 \mathrm{~B}^{3 / 2}}{k^{2}} \mathrm{j}_{J} \quad g_{J} \mathrm{j}_{8^{\prime} 1}^{N R_{J}} \frac{{ }_{n 8}{ }^{\prime} c 8}{{ }_{8}} \frac{U}{\mathrm{l}},
$$

where $c$ denotes either capture ( $($ ) or fission $(f)$. As for the unbroadened case, the total cross section at $E$ is obtained by summing each of the partial cross sections (i.e., scatter, capture and fission).

\section{II.2.4 Monte Carlo Simulation}

Since the URR is an energy region where the parameters for individual resonances cannot be determined, the resonance parameters for the unresolved region are averages of resolved-resonance parameters over an evaluator-defined energy region within the URR. Therefore, Monte Carlo procedures can be used to randomly sample the resonance-parameter distributions for individual resonances within the URR. Sections II.2.1 through II.2.3 provide an overview of the procedures for sampling the resonance parameters and calculating cross sections in the unresolved region.

Since random variables are used in the sampling procedures for the resonance parameters, different resonance parameters and cross sections can be obtained from different random number sequences. However, the Monte Carlo simulation of the problem can estimate the desired cross-section quantity by observing the behavior of a large number of individual histories. ${ }^{H}$ In other words, the exact solution can be approximated if a sufficiently large number of histories are processed. This concept is often referred to as The Law of Large Numbers.

To illustrate the Law of Large Numbers, the first moment or mean value of a probability density function $f(x)$ has the following definition:

${ }^{\mathrm{H}} \mathrm{A}$ history denotes a single calculation or estimate of the total cross-section at an energy $E$ from the sampled resonances and corresponding widths. Note that the capture, fission and scatter cross sections are also calculated as part of a single history. 


$$
x \$^{\prime} \operatorname{m}_{\& 4}^{4} x f(x) d x .
$$

If $n$ random variables (i.e., $x_{1}, x_{2}, \ldots ., x_{n}$ ) are selected according to the PDF $f(x)$, the Monte Carlo estimate of the mean value is given by

$$
\bar{x} \cdot \frac{1}{n} \mathrm{j}_{i^{\prime} 1}^{n} x_{i} .
$$

The estimate, will approach $\$$ as $n$ approaches 4. In like manner, the second moment of $f(x)$ is estimated by

$$
\bar{x}^{2}+\frac{1}{n} j_{i^{\prime} 1}^{n} x_{i}^{2}
$$

The dispersion of $x_{i}$ with respect to 6 can be estimated with the following expression:

$$
\mathrm{F}_{x_{i}}^{2}, \frac{1}{n \& 1} \mathrm{j}_{i^{\prime} 1}^{n}\left(x_{i} \& \bar{x}\right)^{2} \text {. }
$$

Likewise, the variance of 6 is provided by

$$
\mathrm{F}_{\bar{x}}^{2}, \frac{1}{n} \mathrm{~F}_{x_{i}}^{2},
$$

or

$$
\mathrm{F}_{\bar{x}}^{2} \cdot \frac{1}{n(n \& 1)} j_{i^{\prime} 1}^{n}\left(x_{i} \& \bar{x}\right)^{2}
$$

The standard deviation of Gis given by

$$
\mathrm{F}_{\bar{x}} \cdot \sqrt{\mathrm{F}_{\bar{x}}^{2}} .
$$

In Equation (2.36), the value of Gis obtained from $n$ estimates of the mean value. For the purposes of discussion, let the quantity defined by Equation (2.36) constitute a "batch" estimate of the mean value. Furthermore, the $i^{\text {th }}$ estimate of the mean value represents a single history. As a result, there are $n$ histories 
in the batch estimate for $\mathbb{E}$ Using the terminology of a batch, the $j^{\text {th }}$ batch estimate for the mean value can be expressed in the following form:

$$
\bar{x}_{j}, \frac{1}{n} \mathrm{j}_{i^{\prime} 1}^{n} x_{i j} .
$$

In Equation (2.42), $x_{i j}$ represents the $i^{\text {th }}$ estimate in the $j^{\text {th }}$ batch for the mean value. If a different set or batch of $n$ random samples are taken, a different value for 6 would be calculated. Based on the Central Limit Theorem, ${ }^{11}$ if $N$ batch estimates for 6 are obtained, the distribution of 6 will approach a normal distribution as $N$ increases. The Central Limit Theorem implies that the statistical nature of the distribution of 6 is independent of the actual distribution of the individual sample, $x_{i j}$. If $N$ batches are processed, the "grand mean" is calculated by averaging over all the batches:

$$
\bar{x} \cdot \frac{1}{N} \mathrm{j}_{j^{\prime} 1}^{N} \bar{x}_{j} .
$$

The dispersion of $\mathbb{G}$ with respect to 6 is given by

$$
\mathrm{F}_{\bar{x}_{j}}^{2}, \frac{1}{(N \& 1)} \mathrm{j}_{j^{\prime} 1}^{N}\left(\bar{x}_{j} \& \bar{x}\right)^{2}
$$

The variance of the grand mean, $\mathfrak{a}$ is calculated as follows

$$
\mathrm{F}_{\bar{x}}^{2} \cdot \frac{1}{N} \mathrm{~F}_{\bar{x}_{j}}^{2},
$$

Or

$$
\mathrm{F}_{\bar{x}}^{2} \cdot \frac{1}{N(N \& 1)} \mathrm{j}_{j^{\prime} 1}^{N}\left(\bar{x}_{j} \& \bar{x}\right)^{2} .
$$

For $N$ batches, the standard deviation of $\mathbb{G}$ is given by

$$
\mathrm{F}_{\bar{x}}{ }^{\prime} \sqrt{\mathrm{F}_{\bar{x}}^{2}}, \frac{1}{[N(N \& 1)]^{1 / 2}}\left[\mathrm{j}_{j^{\prime} 1}^{N}\left(\bar{x}_{j} \& \bar{x}\right)^{2}\right]^{1 / 2} .
$$

Prior to describing the procedures for constructing a probability table, an explanation of the probability-table structure is needed. The format of a generic probability table with $K$ bands is provided in Table II.1. The band limits in Table II.1 are cross-section band limits that are based on total cross-section values. Note that the determination of the cross-section band limits is provided after the description of the probability-table structure. The band limits increase in value with a corresponding increase in band number. Therefore, the lower cross-section band value for the first band is the minimum band value for the table, and the upper crosssection band value for the last band is the maximum band value for the table. By virtue of the table construction, the cross-section band limits, $B_{k}$, increase monotonically (i.e., $B_{1}<B_{2}<\ldots<B_{K}<B_{K+1}$ ). Since 
the table construction is based on the total cross section, the average value of the total cross section in each band should also increase monotonically with increasing band number (i.e., $\mathbf{G}_{, 1}<\mathbf{G}_{, 2}<\ldots .<\mathbf{G}_{\text {, }}$ ). Note that the band averages for the remaining reaction cross sections are conditional averages corresponding to the average total cross section for the band. Consequently, the band-average cross-section values for capture, fission and scatter will not necessarily increase monotonically.

Table II.1. Example probability-table format

\begin{tabular}{|c|c|c|c|c|c|c|}
\hline Band $(k)$ & Band limits & Probability & $\mathbf{G}_{, k}$ & $\mathbf{G}, k$ & $\mathbf{G}_{, k}$ & $\mathbf{G}_{, k}$ \\
\hline 1 & $B_{1}$ & $\overline{P_{1}}$ & $\mathbf{G}_{1}$ & $\mathrm{G}, 1$ & $\mathrm{G}_{1,1}$ & $\mathbf{G}_{, 1}$ \\
\hline 2 & $B_{2}$ & $P_{2}$ & $\mathbf{G}_{12}$ & $\mathbf{G}, 2$ & $\mathrm{G}, 2$ & $\mathbf{G}_{, 2}$ \\
\hline 3 & $B_{3}$ & $P_{3}$ & $\mathbf{G}_{, 3}$ & $\mathbf{G}, 3$ & $\mathbf{G}_{3,3}$ & $\mathbf{G}_{, 3}$ \\
\hline @ & @ & @ & @ & @ & @ & @ \\
\hline @ & @ & @ & @ & @ & @ & @ \\
\hline @ & @ & @ & @ & @ & @ & @ \\
\hline @ & @ & @ & @ & @ & @ & @ \\
\hline$K$ & $\begin{array}{c}B_{K} \\
B_{K+1}\end{array}$ & $P_{K}$ & $\mathbf{G}_{, K}$ & $\mathbf{G}, K$ & $\mathbf{G}_{, K}$ & $\mathbf{G}_{, K}$ \\
\hline
\end{tabular}

As noted previously, the cross-section band values for each probability table are based on the total cross section. In PURM, the user has the option to specify the band values for each table or allow the code to determine the appropriate cross-section band values for each table. The determination of the cross-section bands for each table is a rather arbitrary process. For instance, bands may be constructed to be equally spaced or increase in a geometric pregression (e.g., $B_{1}, B_{2}=c B_{1}, B_{3}=c^{2} B_{1}$, etc., where $c$ is a constant). In PURM, the cross-section band values are calculated with the following expression:

$$
B_{k}{ }^{\prime} B_{\min }\left(\frac{B_{\max }}{B_{\min }}\right)^{\frac{k \& 2}{K \& 2}} ; k^{\prime} 2,3, \ldots ., K,
$$

where

$$
\begin{array}{lll}
B_{\min }= & \text { lower bound for the second band (i.e., } \left.B_{2}\right) \\
B_{\max }= & \text { lower bound for the last band (i.e., } \left.B_{K}\right)
\end{array}
$$

The values of $B_{\min }$ and $B_{\max }$ can be specified by the user or determined by the code. If the user does not specify the values of $B_{\min }$ and $B_{\max }$, PURM estimates these values by performing a Monte Carlo simulation using up to 50 histories prior to performing the actual calculation. Once the values of $B_{\min }$ and $B_{\max }$ are established, PURM uses Equation (2.48) to construct the cross-section band limits for each probability table. Note that $B_{1}$ and $B_{K+1}$ are not determined prior to the calculation of a probability table. The values of $B_{1}$ and $B_{K+1}$ represent the absolute minimum and maximum cross-section values of the Monte Carlo simulation. As a result, the absolute minimum and maximum cross-section values are determined during the calculation of each probability table. The value of $B_{1}$ must be $\$ 0$ and $<B_{2}$, and the value of $B_{K+1}$ can be any value that is greater than $B_{K}$. 
Once the cross-section band limits are established for a table, PURM performs a Monte Carlo simulation for each table using a specified number of iterations or histories for a specified number of batches. For a single history in PURM, the procedures of Section II.2.1 and II.2.2 are used to sample the resonance parameters for the reference energy point in the URR. Subsequently, the formulae of Section II.2.3 are used to calculate the scatter, capture, fission and total cross sections at the reference energy. As noted previously, the calculation of the total cross section and corresponding partial reactions at the reference energy constitute a single history.

For each history in a batch, the calculated total cross-section value is compared with the cross-section band limits for the table. The total cross-section is added to the appropriate cross-section band (i.e., $k^{\text {th }}$ band) within the probability table. In addition, a counter assigned to the band is advanced by unity. The corresponding band values for the scatter, capture and fission cross sections are also added to the appropriate registers for the $k^{\text {th }}$ band. Note that the band selection for the partial reactions is based on the value of the total cross section. At the completion of the number of histories for the batch, the mean value for the total cross section for the $k^{\text {th }}$ band (i.e., $\mathbf{G}_{, k}$ ) is calculated by dividing the cumulative sum for the band by the number of tallies within the band. The corresponding average band values for the scatter, capture and fission cross sections are calculated in a similar manner to the total cross-section. The batch estimate for the probability for each band is obtained by dividing the number of tallies for the band by the number of histories in a batch. Once the initial batch is completed, the next batch is processed using the same procedure for each history in a batch. The calculation for a table is complete when all of the batches have been processed.

Due to the nature of the calculational procedures, PURM provides a mechanism for monitoring the convergence of the cross-section calculation. During the Monte Carlo calculation for a table, PURM stores a "running" average (i.e., by batch processed) of the total, capture, fission and scatter cross section for the entire probability table. Plotting routines were developed and added to PURM to plot the cross-section calculation by batches run and skipped. The plotting subroutines are based on the subroutines in KENO $\mathrm{V} . \mathrm{a} ;{ }^{12}$ however, the subroutines were re-written for implementation in PURM.

For each reaction, a plot of the calculated cross section is provided by batches run and skipped. In a Monte Carlo simulation for a radiation transport problem, an initial number of batches are skipped to ensure that the particle source distribution is converged and not "contaminated" by the initial guess for the source distribution. For the calculation of probability tables, the Monte Carlo procedure does not deal with a source distribution of particles; therefore, skipping an initial number of batches does not have an analogous physical interpretation as described for a radiation transport problem. Nonetheless, the user has the option to specify an initial number of batches to skip in the calculation, and the code may increase the number of batches to skip based on the calculated standard deviation within the first few batches. In particular, the code calculates the average cross-section value by skipping additional batches. Each time the number of batches to skip is increased, the code calculates the average cross-section value and standard deviation for the remaining active batches. Subsequently, PURM evaluates the calculated average cross section as a function of batches skipped up through $2 / 3$ the number of batches processed (i.e., skip up to $2 / 3$ the number of batches run). The code searches for the calculated average cross section with the smallest standard deviation and prints this average value with the corresponding skipped number of batches in the plot by batches skipped. The crosssection plots for the Monte Carlo simulation permit the user to evaluate the convergence of the calculation. After plotting the average cross section by batches run and skipped, PURM provides histogram frequency plots for each reaction and performs a $\mathrm{P}^{2}$-test for normality for each reaction. 


\section{RESULTS}

In an effort to test the code, PURM was used to calculate probability tables for ENDF/B-VI ${ }^{235} \mathrm{U}$ (MAT = 9228). Results are provided in this section to demonstrate the capabilities of PURM. In addition, comparisons are made with the NJOY module PURR to verify the calculational results obtained with PURM.

For ENDF/B-VI ${ }^{235} \mathrm{U}$, the unresolved-resonance region extends from $2.25 \mathrm{keV}$ to $25 \mathrm{keV}$, and the evaluation has 14 reference energies in the URR. PURM was used to calculate 14 probability tables that correspond to the reference energies in the evaluation. Each probability table was calculated at $300 \mathrm{~K}$ using 200 batches with 50 histories per batch for a total of 10,000 histories per table. The total number of histories is relatively low compared with typical Monte Carlo radiation transport calculations (e.g., deep-penetration shielding problems, eigenvalue calculations, etc.). Fortunately, probability-table calculations do not have the complexities that are associated with radiation transport problems (e.g., complex geometry, particle streaming, etc.). As a result, the calculation of probability tables is a generally well-behaved problem. Therefore, a relatively large number of histories is not required to obtain acceptable statistics in a probability-table calculation.

The average cross-section values that were calculated by PURM at each of the 14 reference energies are provided in Table III.1. The average cross sections provided by PURM represent the average cross-section values for the probability table at each reference energy point. For comparison purposes, the AMPX module PRUDE was used to calculate infinite-dilution cross sections at each energy point in the URR, and the PRUDE-calculated infinite-dilution values are also presented in Table III.1. PRUDE calculates average cross-section values as a function of temperature and dilution in the URR from the average unresolvedresonance parameters that are provided in an ENDF/B evaluation. Consequently, the average infinite-dilution cross-section values from PRUDE should agree with the average cross-section values (i.e., average crosssection values for a table) from PURM. Based on the results in Table III.1, the average cross-section values from PURM agree with the infinite-dilution values that were calculated with PRUDE. 


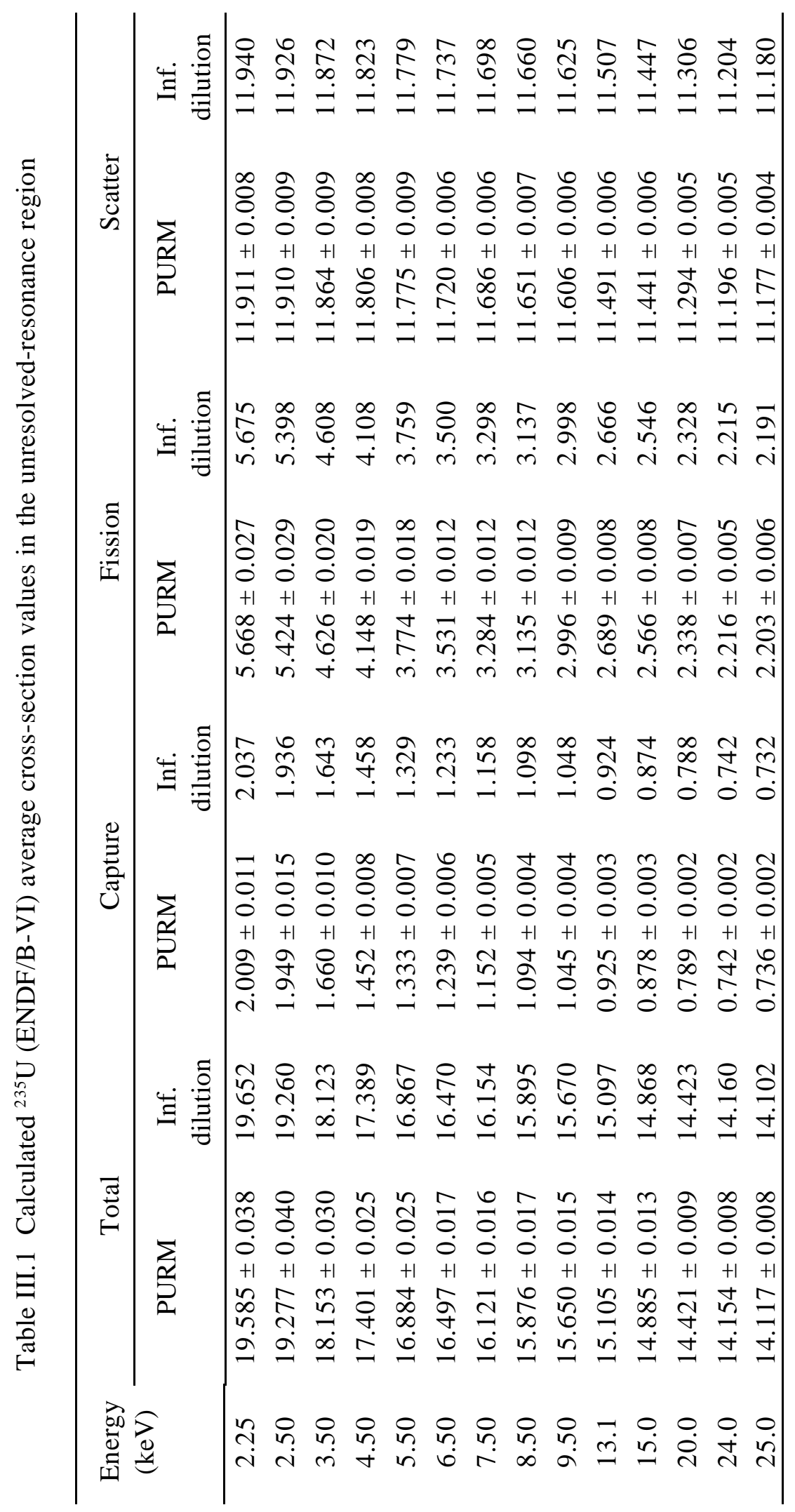


As noted previously, a probability table was calculated for each reference energy in the URR. To illustrate the results from PURM, the calculated results for the probability table at $2.25 \mathrm{keV}$ are presented in this section. Since the results for the remaining 13 tables are similar to the results for the first table, all 14 tables are not presented in this report. The results for the first table are presented to demonstrate the calculational capabilities in PURM.

Because of the nature of the Monte Carlo calculation, PURM provides a mechansim for monitoring the convergence of each probability-table calculation. For the probability table at $2.25 \mathrm{keV}$, Figures III.1 and III. 2 provide a plot of the total cross-section calculation as a function of batches run and skipped, respectively. As shown in Figure III.1, convergence for the total cross section is achieved after completion of the specified number of batches processed. Similar results are obtained for the capture, fission and scatter cross sections. Figure III.3 provides a frequency plot distribution for the batches processed during the total cross-section calculation. In addition, Figure III.3 provides the results for the $\mathrm{P}^{2}$-test for normality. As indicated in Figure III.3, the frequency distribution for the total cross-section calculation satisfies the $\mathrm{P}^{2}$-test for normality at the $95 \%$ confidence level.

The calculated probability table at $2.25 \mathrm{keV}$ is provided in Figure III.4. As shown in Figure III.4, PURM provides the MAT number, temperature and energy value for the probability table. For the ${ }^{235} \mathrm{U}$ calculation, PURM was instructed to calculate probability tables with 20 cross-section bands. Although the user can specify the boundaries of each cross-section band, the cross-section bands that are presented in Figure III.4 were determined by PURM during the Monte Carlo calculation. The probability and standard deviation associated with each band are also provided in Figure III.4. Moreover, the average cross-section values and standard deviations for the total, capture, fission and scatter cross-sections are provided for each band within the probability table. Following the probability-table values in Figure III. 4 are the average cross-section values for the calculated probability table and the results of the ) ${ }_{3}$-statistics test.

To help visualize the calculated results for the probability table in Figure III.4, the probabilities as a function of the cross-section bands are plotted in Figure III.5. Likewise, the average total, capture, fission and scatter cross sections are plotted in Figures III.6 through III.9, respectively. Note that the average total cross section as a function of band number in Figure III.6 increases monotonically with increasing band number. For some of the cross-section plots, the error bars for some of the cross-section values may be too small relative to the cross-section value to display in the plot. 


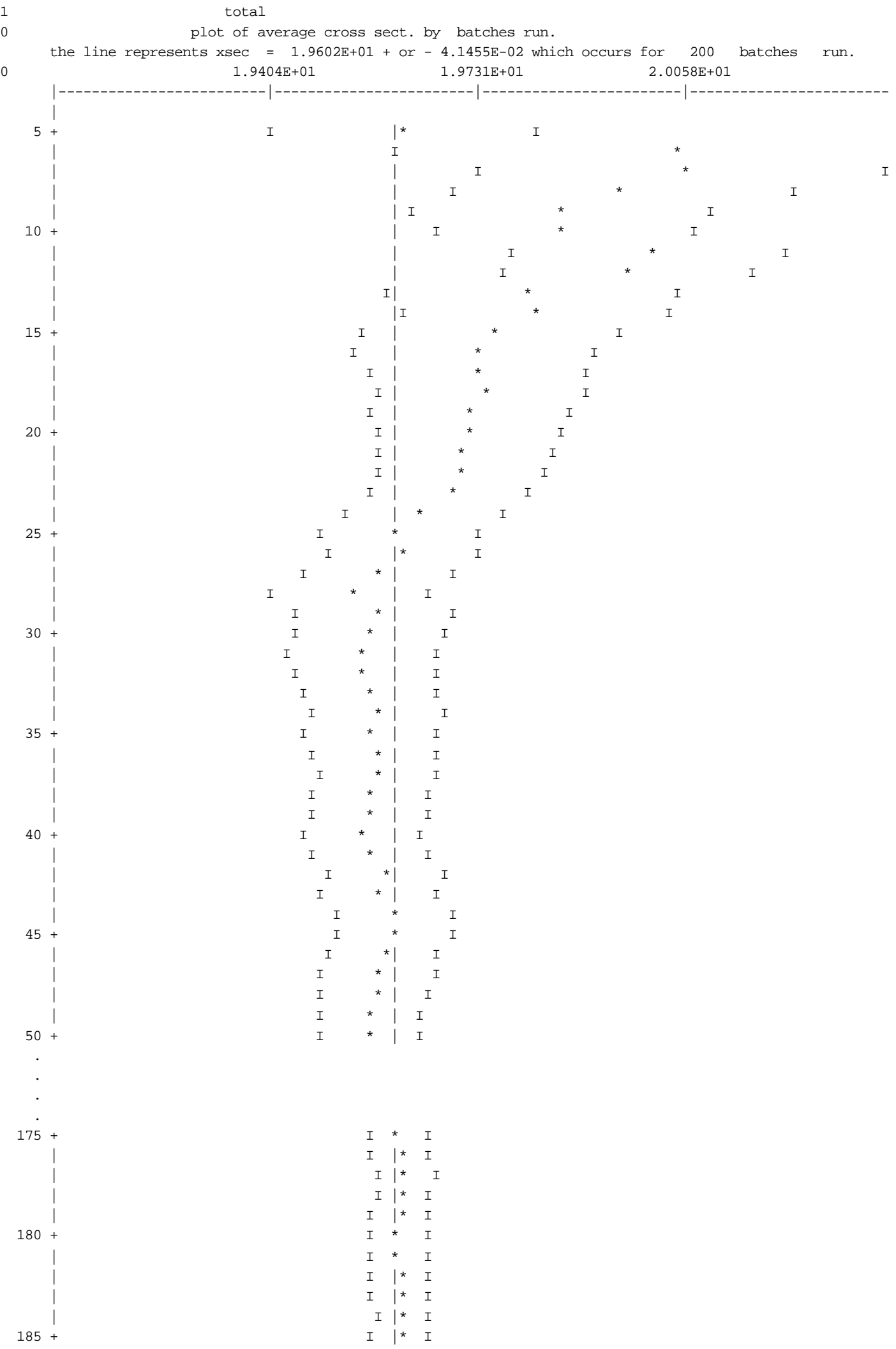

Figure III.1. Calculated average total cross section by batches run. 


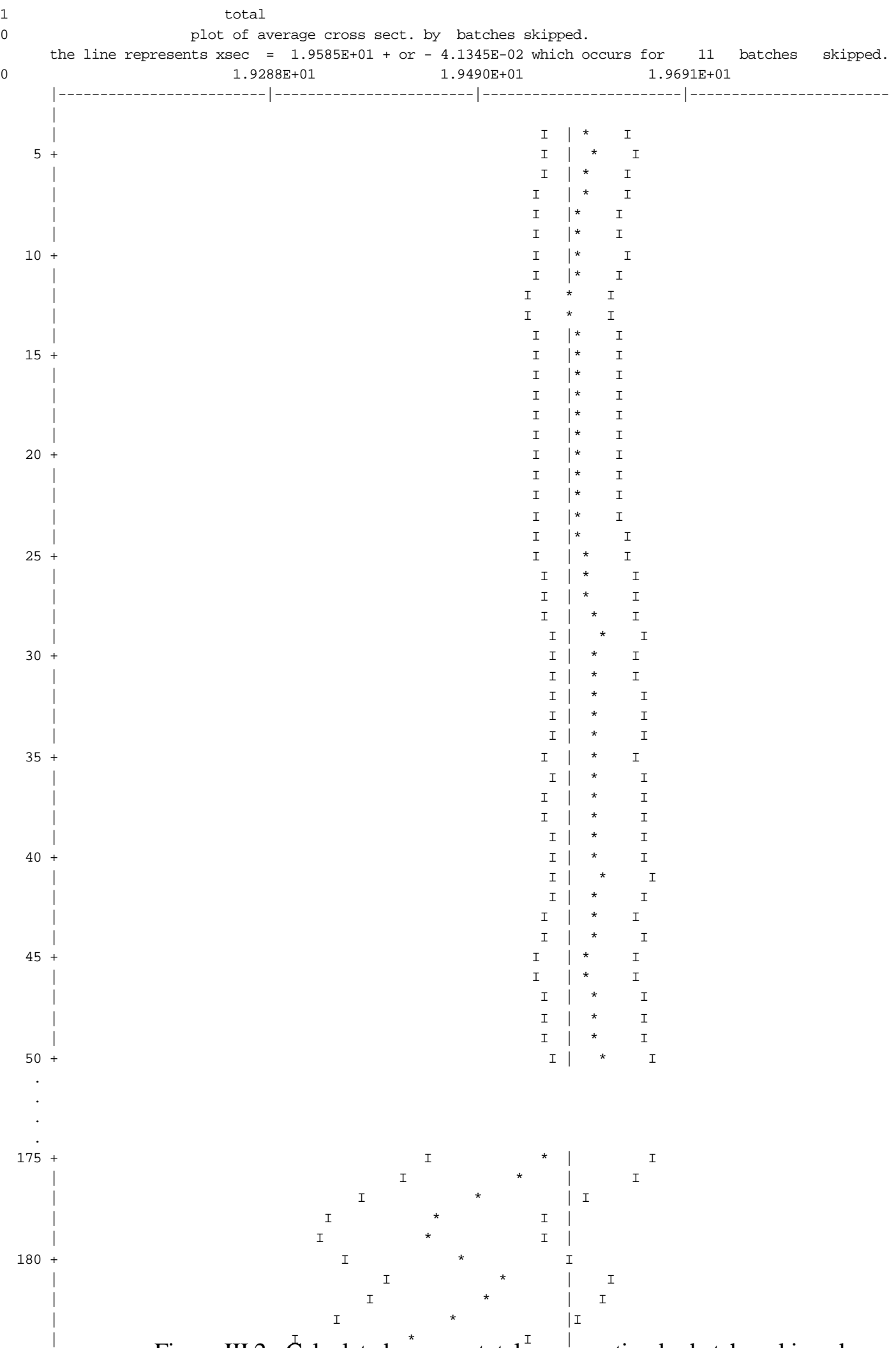

Figure III.2. Calculated average total ${ }^{\mathrm{I}}$ cross section by batches skipped. 


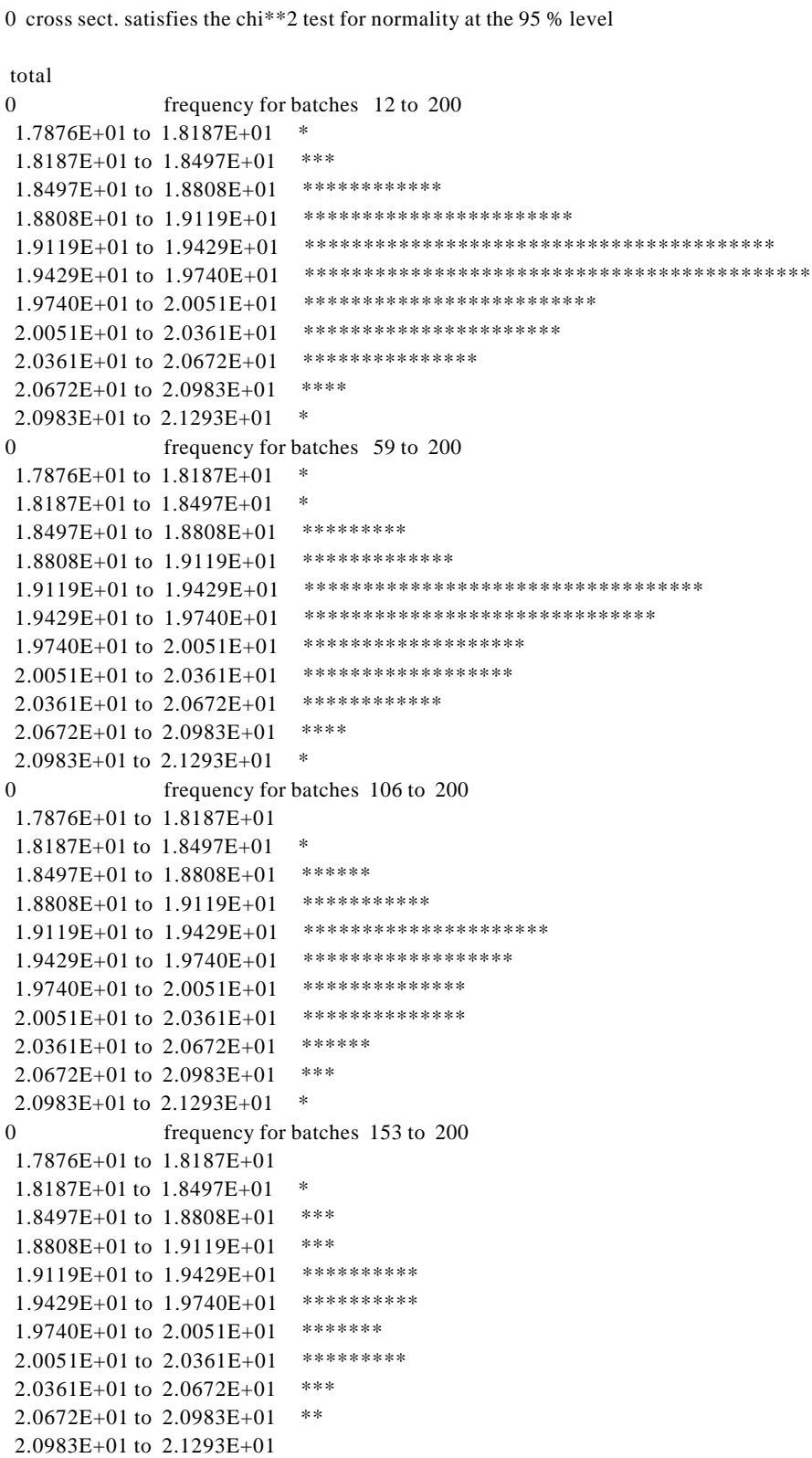

Figure III.3. Frequency distribution for ${ }^{235} \mathrm{U}$ total cross-section calculation at $2.25 \mathrm{keV}$. 
Probability Tables for MAT: 9228

Temperature (K): $3.000 \mathrm{E}+02$

\begin{tabular}{|c|c|c|c|c|c|c|c|c|c|c|c|}
\hline \multirow{2}{*}{$\begin{array}{c}\text { Band } \\
----- \\
1\end{array}$} & \multirow{2}{*}{$\begin{array}{l}\text { Band limits } \\
1.1921 \mathrm{E}+01\end{array}$} & \multirow{2}{*}{ Probability } & \multirow{2}{*}{$\begin{array}{c}\text { Std. Dev. } \\
8.7828 \mathrm{E}-04\end{array}$} & \multirow{2}{*}{$\begin{array}{c}\text { Total } \\
1.2675 \mathrm{E}+01\end{array}$} & \multirow{2}{*}{$\begin{array}{l}\text { Std. Dev. } \\
2.9362 \mathrm{E}-02\end{array}$} & \multirow{2}{*}{$\begin{array}{l}\text { Capture S } \\
4.2952 \mathrm{E}-01\end{array}$} & Std. Dev. & Fission & Std. Dev. & Scatter & Std. Dev. \\
\hline & & & & & & & $2.1405 \mathrm{E}-02$ & $2 \quad 1.2673 \mathrm{E}+00$ & $4.3068 \mathrm{E}-02$ & $1.0991 \mathrm{E}+01$ & $4.9198 \mathrm{E}-02$ \\
\hline 2 & $1.3018 \mathrm{E}+01$ & $2.4264 \mathrm{E}-02$ & $1.4588 \mathrm{E}-03$ & $1.3459 \mathrm{E}+01$ & $1.6643 \mathrm{E}-02$ & $5.2254 \mathrm{E}-01$ & $1 \quad 1.6204 \mathrm{E}-02$ & $2 \quad 1.6695 \mathrm{E}+00$ & $3.1193 \mathrm{E}-02$ & $1.1265 \mathrm{E}+01$ & $3.6077 \mathrm{E}-02$ \\
\hline 3 & $1.3741 \mathrm{E}+01$ & 4.6497E-02 & $1.8325 \mathrm{E}-03$ & $1.4223 \mathrm{E}+01$ & $1.1407 \mathrm{E}-02$ & $6.9073 \mathrm{E}-01$ & $1.6126 \mathrm{E}-02$ & $22.1465 \mathrm{E}+00$ & $3.2474 \mathrm{E}-02$ & $1.1390 \mathrm{E}+01$ & $3.7881 \mathrm{E}-02$ \\
\hline 4 & $1.4505 \mathrm{E}+01$ & 7.7157E-02 & $3.3293 \mathrm{E}-03$ & $1.5037 \mathrm{E}+01$ & $9.3146 \mathrm{E}-03$ & $8.6082 \mathrm{E}-01$ & $1 \quad 1.4011 \mathrm{E}-02$ & $22.6825 \mathrm{E}+00$ & $2.2085 \mathrm{E}-02$ & $1.1493 \mathrm{E}+01$ & $2.6287 \mathrm{E}-02$ \\
\hline 5 & $1.5310 \mathrm{E}+01$ & $9.4213 \mathrm{E}-02$ & $3.0515 \mathrm{E}-03$ & $1.5906 \mathrm{E}+01$ & $8.5090 \mathrm{E}-03$ & $1.0720 \mathrm{E}+00$ & $0 \quad 1.7995 \mathrm{E}-02$ & $2 \quad 3.2613 \mathrm{E}+00$ & $2.6666 \mathrm{E}-02$ & $1.1578 \mathrm{E}+01$ & $2.8329 \mathrm{E}-02$ \\
\hline 6 & $1.6161 \mathrm{E}+01$ & $1.0051 \mathrm{E}-01$ & $3.3825 \mathrm{E}-03$ & $1.6825 \mathrm{E}+01$ & $1.1116 \mathrm{E}-02$ & $1.2835 \mathrm{E}+00$ & $0 \quad 2.0811 \mathrm{E}-02$ & $2 \quad 3.9222 \mathrm{E}+00$ & $2.8543 \mathrm{E}-02$ & $1.1618 \mathrm{E}+01$ & $3.2344 \mathrm{E}-02$ \\
\hline 7 & $1.7058 \mathrm{E}+01$ & $1.0162 \mathrm{E}-01$ & $3.6525 \mathrm{E}-03$ & $1.7822 \mathrm{E}+01$ & $9.5516 \mathrm{E}-03$ & $1.5563 \mathrm{E}+00$ & $0 \quad 2.1998 \mathrm{E}-02$ & $2 \quad 4.5318 \mathrm{E}+00$ & $3.7133 \mathrm{E}-02$ & $1.1729 \mathrm{E}+01$ & $3.2315 \mathrm{E}-02$ \\
\hline 8 & $1.8006 \mathrm{E}+01$ & $1.0508 \mathrm{E}-01$ & $3.1872 \mathrm{E}-03$ & $1.8863 \mathrm{E}+01$ & $1.2467 \mathrm{E}-02$ & $1.8421 \mathrm{E}+00$ & $0 \quad 2.4150$ E-02 & $2 \quad 5.2154 \mathrm{E}+00$ & 3.3944E-02 & $1.1812 \mathrm{E}+01$ & $2.8696 \mathrm{E}-02$ \\
\hline 9 & $1.9006 \mathrm{E}+01$ & $9.5939 \mathrm{E}-02$ & $3.1619 \mathrm{E}-03$ & $1.9969 \mathrm{E}+01$ & $1.0160 \mathrm{E}-02$ & $2.0899 \mathrm{E}+00$ & $0 \quad 3.3737 \mathrm{E}-02$ & $25.9838 \mathrm{E}+00$ & $4.8687 \mathrm{E}-02$ & $1.1895 \mathrm{E}+01$ & $2.8160 \mathrm{E}-02$ \\
\hline 10 & $2.0061 \mathrm{E}+01$ & 8.0609E-02 & $2.7258 \mathrm{E}-03$ & $2.1109 \mathrm{E}+01$ & 1.4049E-02 & $2.3322 \mathrm{E}+00$ & $0 \quad 5.0809 \mathrm{E}-02$ & $2 \quad 6.7551 \mathrm{E}+00$ & $5.9422 \mathrm{E}-02$ & $1.2013 \mathrm{E}+01$ & $3.8397 \mathrm{E}-02$ \\
\hline 11 & $2.1176 \mathrm{E}+01$ & $6.7716 \mathrm{E}-02$ & $2.8857 \mathrm{E}-03$ & $2.2374 \mathrm{E}+01$ & $1.8752 \mathrm{E}-02$ & $2.6047 \mathrm{E}+00$ & $0 \quad 4.7779 \mathrm{E}-02$ & $27.6429 \mathrm{E}+00$ & 6.9972E-02 & $1.2115 \mathrm{E}+01$ & 4.7998E-02 \\
\hline 12 & $2.2352 \mathrm{E}+01$ & $6.1320 \mathrm{E}-02$ & $2.1342 \mathrm{E}-03$ & $2.3642 \mathrm{E}+01$ & $1.7964 \mathrm{E}-02$ & $2.9610 \mathrm{E}+00$ & $0 \quad 6.3559 \mathrm{E}-02$ & $28.2799 \mathrm{E}+00$ & $1.0026 \mathrm{E}-01$ & $1.2384 \mathrm{E}+01$ & 4.8154E-02 \\
\hline 13 & $2.3593 \mathrm{E}+01$ & 4.6396E-02 & $2.0981 \mathrm{E}-03$ & $2.5054 \mathrm{E}+01$ & $2.5821 \mathrm{E}-02$ & $3.4068 \mathrm{E}+00$ & $0 \quad 7.4735 \mathrm{E}-02$ & $29.1864 \mathrm{E}+00$ & $1.1121 \mathrm{E}-01$ & $1.2447 \mathrm{E}+01$ & 4.7947E-02 \\
\hline 14 & $2.4904 \mathrm{E}+01$ & $3.4924 \mathrm{E}-02$ & $1.6065 \mathrm{E}-03$ & $2.6496 \mathrm{E}+01$ & $2.6593 \mathrm{E}-02$ & $3.7403 \mathrm{E}+00$ & $0 \quad 9.1238 \mathrm{E}-02$ & $2 \quad 1.0173 \mathrm{E}+01$ & $1.1995 \mathrm{E}-01$ & $1.2580 \mathrm{E}+01$ & $6.9898 \mathrm{E}-02$ \\
\hline 15 & $2.6287 \mathrm{E}+01$ & $2.4365 \mathrm{E}-02$ & $1.5716 \mathrm{E}-03$ & $2.8120 \mathrm{E}+01$ & $2.8053 \mathrm{E}-02$ & $4.1111 \mathrm{E}+00$ & $0 \quad 1.0631 \mathrm{E}-01$ & $11.1104 \mathrm{E}+01$ & $1.7389 \mathrm{E}-01$ & $1.2952 \mathrm{E}+01$ & $8.4353 \mathrm{E}-02$ \\
\hline 16 & $2.7747 \mathrm{E}+01$ & $1.5228 \mathrm{E}-02$ & $1.0609 \mathrm{E}-03$ & $2.9690 \mathrm{E}+01$ & 3.6419E-02 & $4.8580 \mathrm{E}+00$ & $0 \quad 1.4322 \mathrm{E}-01$ & $1 \quad 1.1886 \mathrm{E}+01$ & $2.5025 \mathrm{E}-01$ & $1.2959 \mathrm{E}+01$ & $1.1861 \mathrm{E}-01$ \\
\hline 17 & $2.9288 \mathrm{E}+01$ & $8.8325 \mathrm{E}-03$ & $9.3345 \mathrm{E}-04$ & $3.1369 \mathrm{E}+01$ & $5.0699 \mathrm{E}-02$ & $5.1322 \mathrm{E}+00$ & $0 \quad 1.7892 \mathrm{E}-01$ & $1 \quad 1.2935 \mathrm{E}+01$ & $2.9275 \mathrm{E}-01$ & $1.3282 \mathrm{E}+01$ & $1.5762 \mathrm{E}-01$ \\
\hline 18 & $3.0915 \mathrm{E}+01$ & 4.0609E-03 & $5.7617 \mathrm{E}-04$ & $3.3304 \mathrm{E}+01$ & $1.0428 \mathrm{E}-01$ & $5.6434 \mathrm{E}+00$ & $\begin{array}{l}0 \\
0.9659 \mathrm{E}-01\end{array}$ & $1 \quad 1.3817 \mathrm{E}+01$ & $4.0444 \mathrm{E}-01$ & $1.3799 \mathrm{E}+01$ & $2.3423 \mathrm{E}-01$ \\
\hline 19 & $3.2632 \mathrm{E}+01$ & $3.0457 \mathrm{E}-03$ & $5.3591 \mathrm{E}-04$ & $3.5110 \mathrm{E}+01$ & $1.1511 \mathrm{E}-01$ & $6.5815 \mathrm{E}+00$ & $0 \quad 4.0004 \mathrm{E}-01$ & $1 \quad 1.4790 \mathrm{E}+01$ & $5.9847 \mathrm{E}-01$ & $1.3767 \mathrm{E}+01$ & $2.3685 \mathrm{E}-01$ \\
\hline 20 & $3.6358 \mathrm{E}+01$ & $1.5228 \mathrm{E}-03$ & $3.7488 \mathrm{E}-04$ & $3.9257 \mathrm{E}+01$ & $7.8542 \mathrm{E}-01$ & $8.3592 \mathrm{E}+00$ & $\begin{array}{ll}0 & 6.2110 \mathrm{E}-01\end{array}$ & $1 \quad 1.5744 \mathrm{E}+01$ & $9.3549 \mathrm{E}-01$ & $1.5155 \mathrm{E}+01$ & $2.9463 \mathrm{E}-01$ \\
\hline & $4.9043 \mathrm{E}+01$ & & & & & & & & & & \\
\hline
\end{tabular}

Average Cross Sections for Table:

Total: $1.9585 \mathrm{E}+01(3.7760 \mathrm{E}-02)$

Scat: $1.1911 \mathrm{E}+01(8.1690 \mathrm{E}-03)$

Fiss: $5.6682 \mathrm{E}+00(2.6932 \mathrm{E}-02)$

Cap: $2.0094 \mathrm{E}+00(1.1436 \mathrm{E}-02)$

DYSON AND MEHTA LONG-RANGE CORRELATION OF DELTA-3 STATISTICS TEST for isotope: 1 of 1

L J Delta3-Theory Std. Dev. Delta3 No. of Levels No. of Pairs N(E)=a*E(nres)+b a $\quad$ b

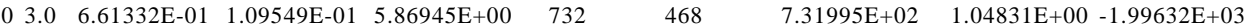

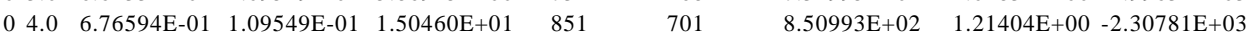

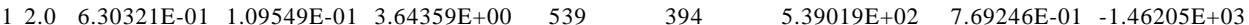

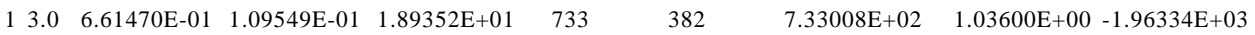

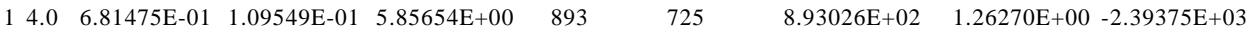

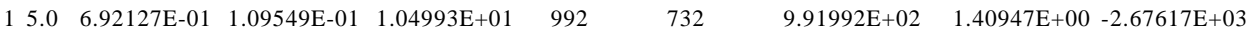

Figure III.4. Calculated probability table for ${ }^{235} \mathrm{U}$ at $2.25 \mathrm{keV}$. 


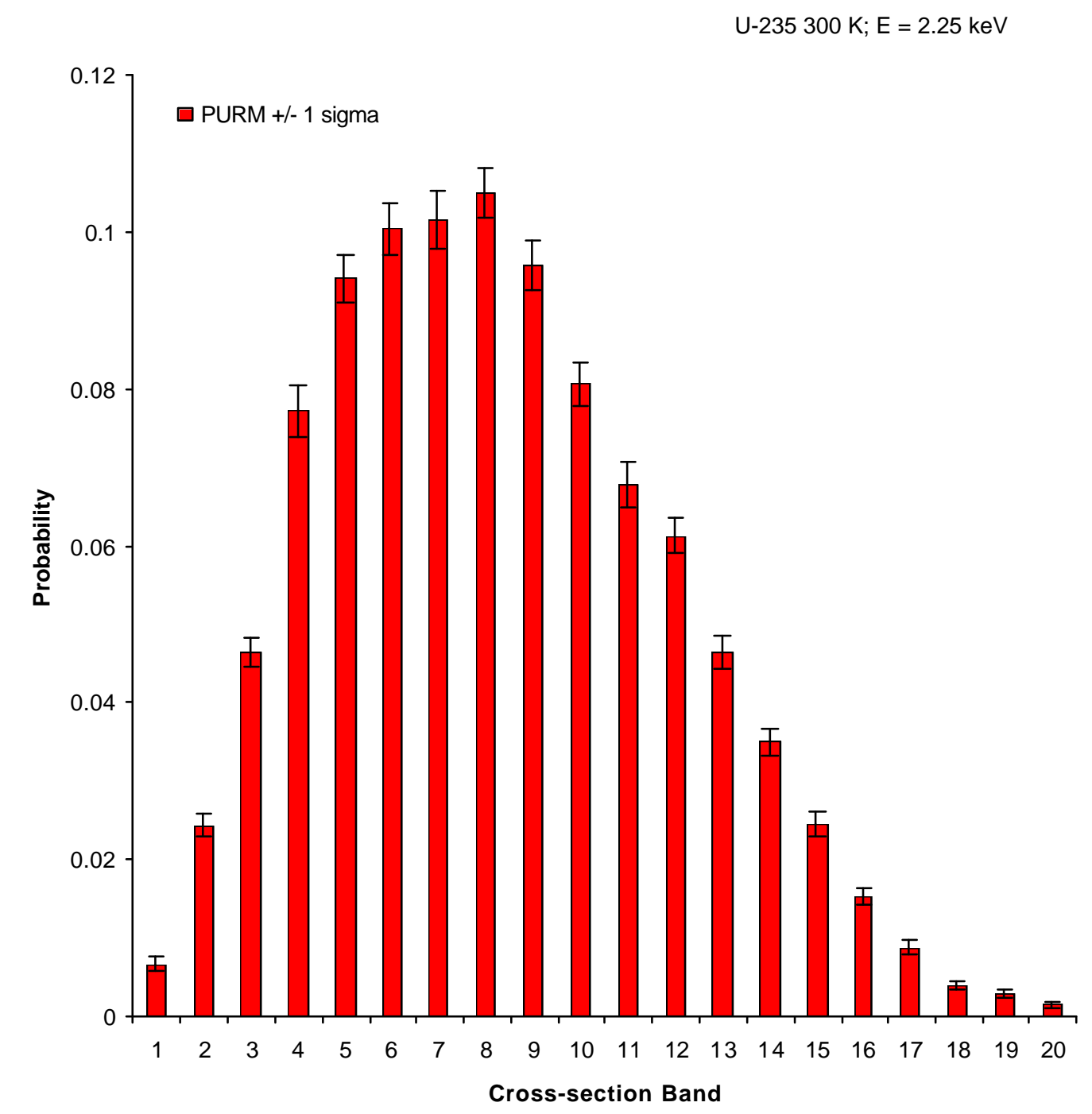

Figure III.5. Calculated probabilities as a function of cross-section band for ${ }^{235} \mathrm{U}$ at $2.25 \mathrm{keV}$. 


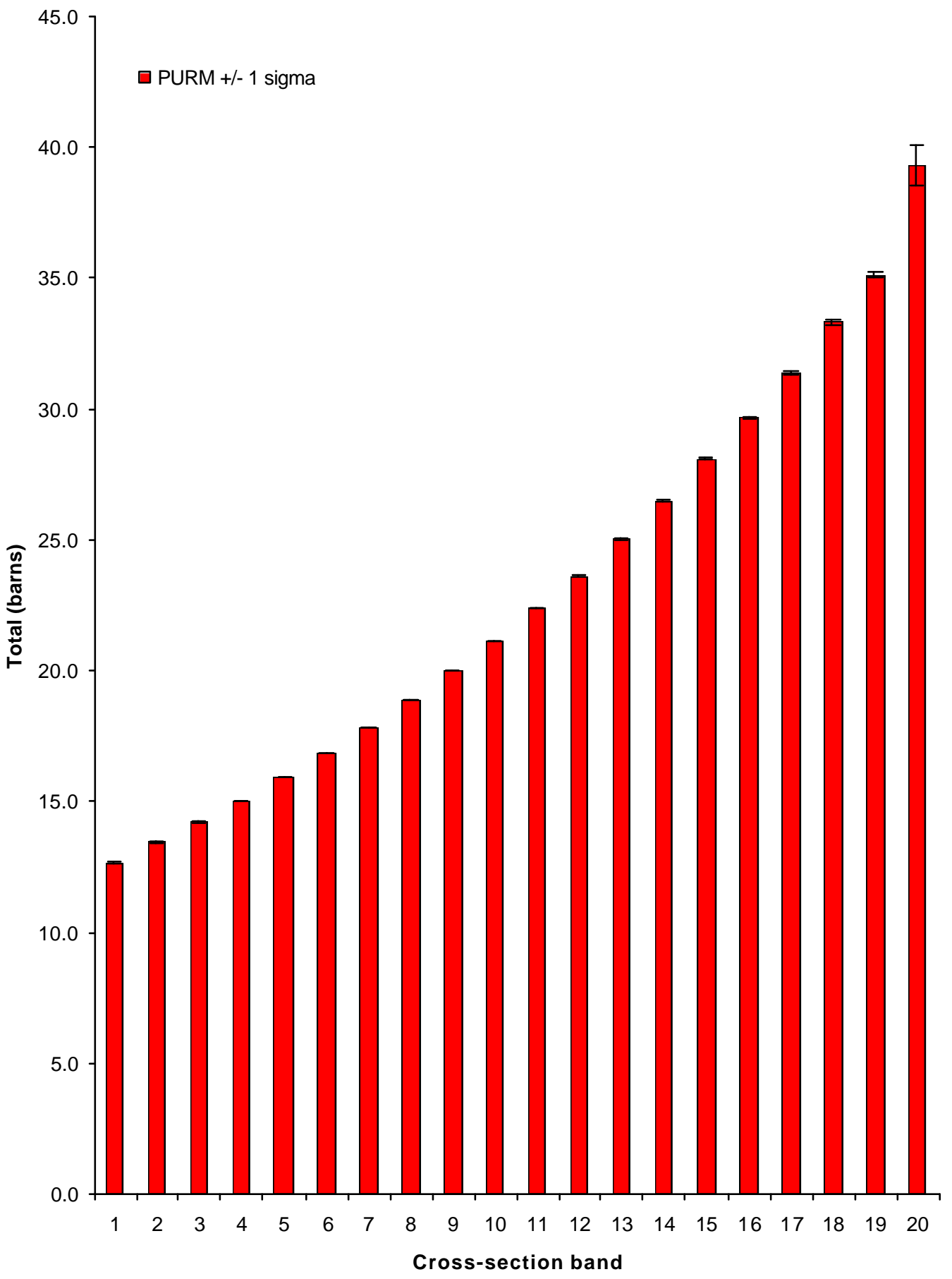

Figure III.6. Calculated total cross section as a function of cross-section band for ${ }^{235} \mathrm{U}$ at $2.25 \mathrm{keV}$. 


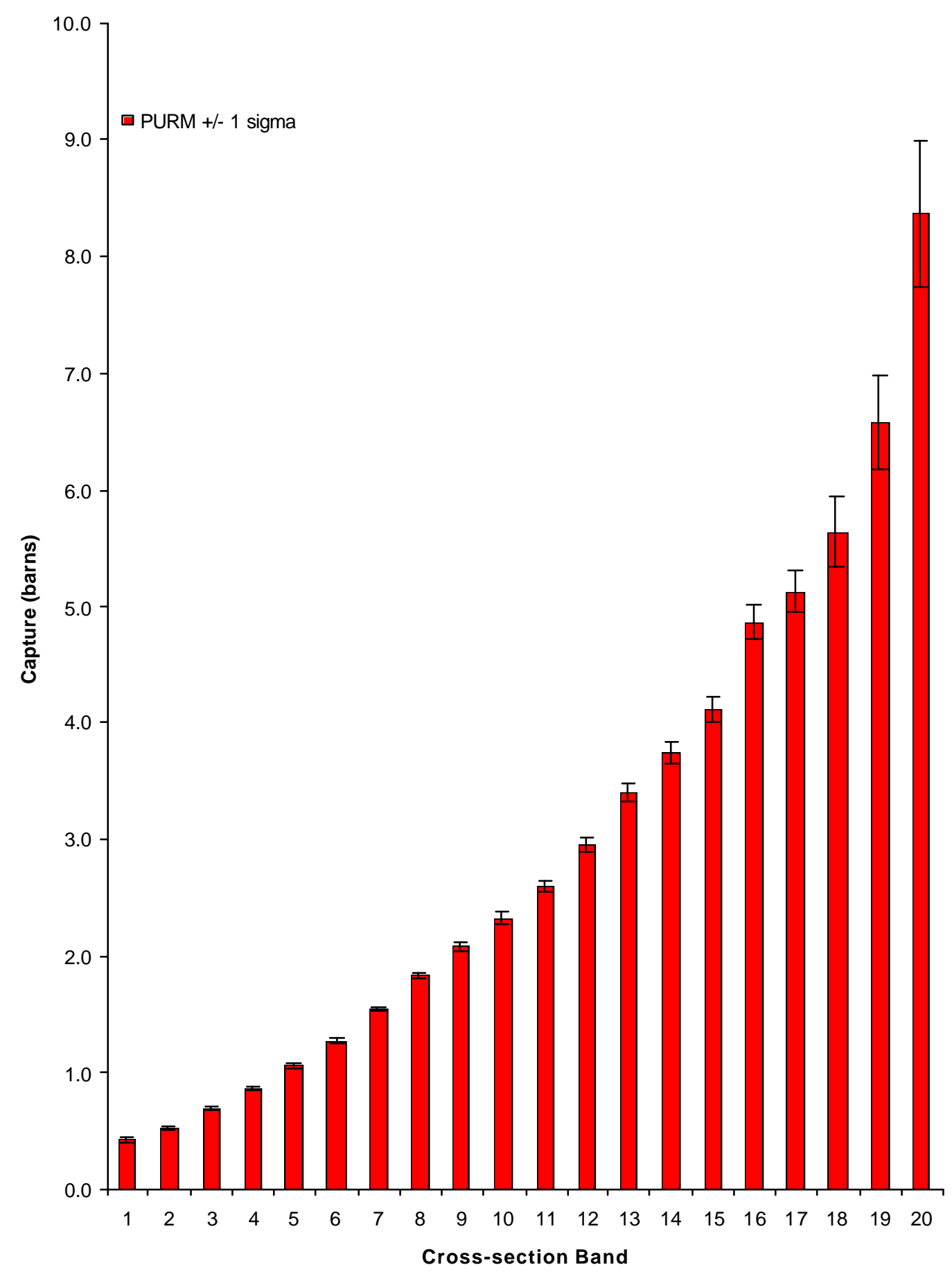

Figure III.7. Calculated capture cross section as a function of cross-section band for ${ }^{235} \mathrm{U}$ at $2.25 \mathrm{keV}$. 


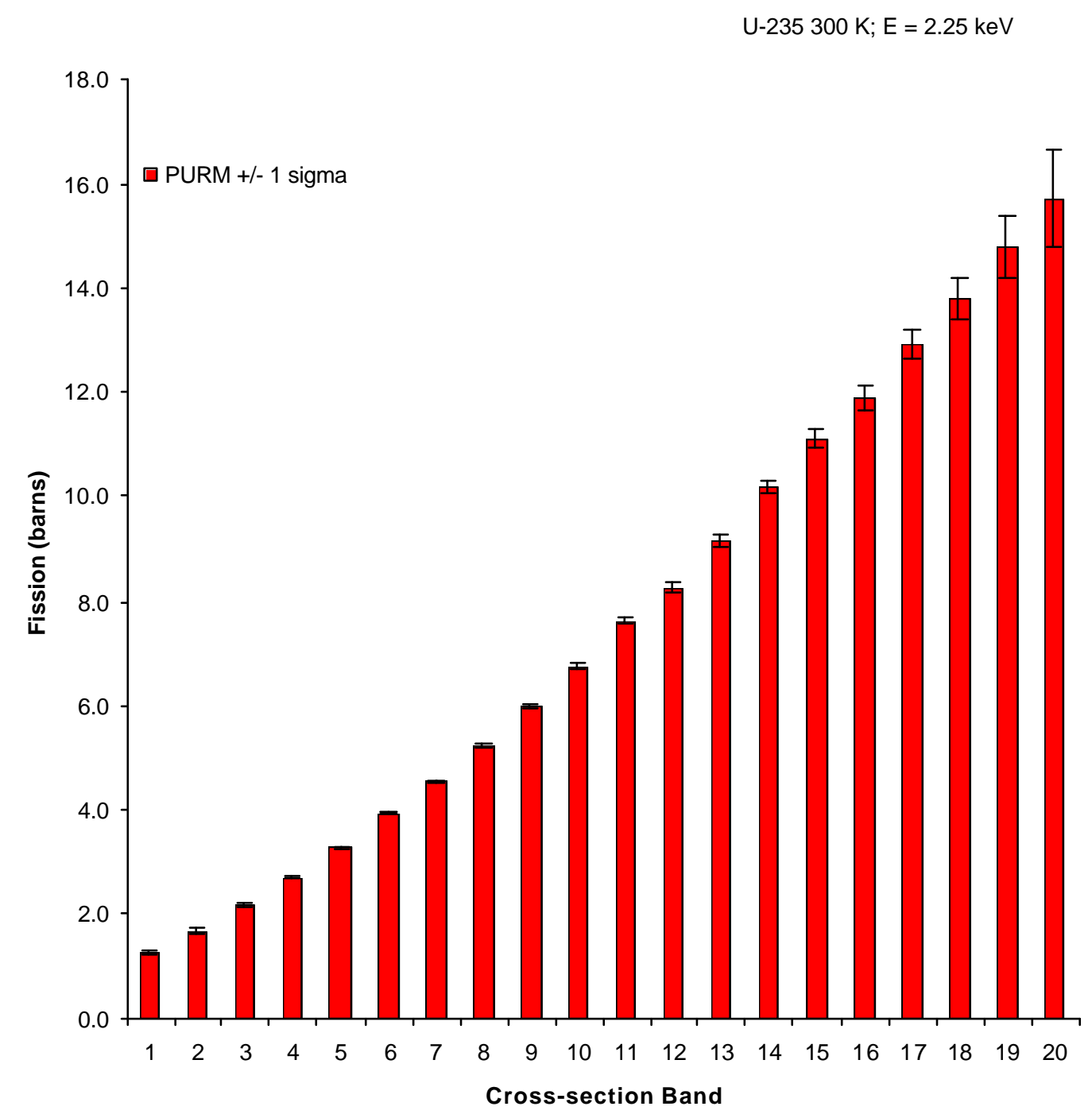

Figure III.8. Calculated fission cross section as a function of cross-section band for ${ }^{235} \mathrm{U}$ at $2.25 \mathrm{keV}$. 


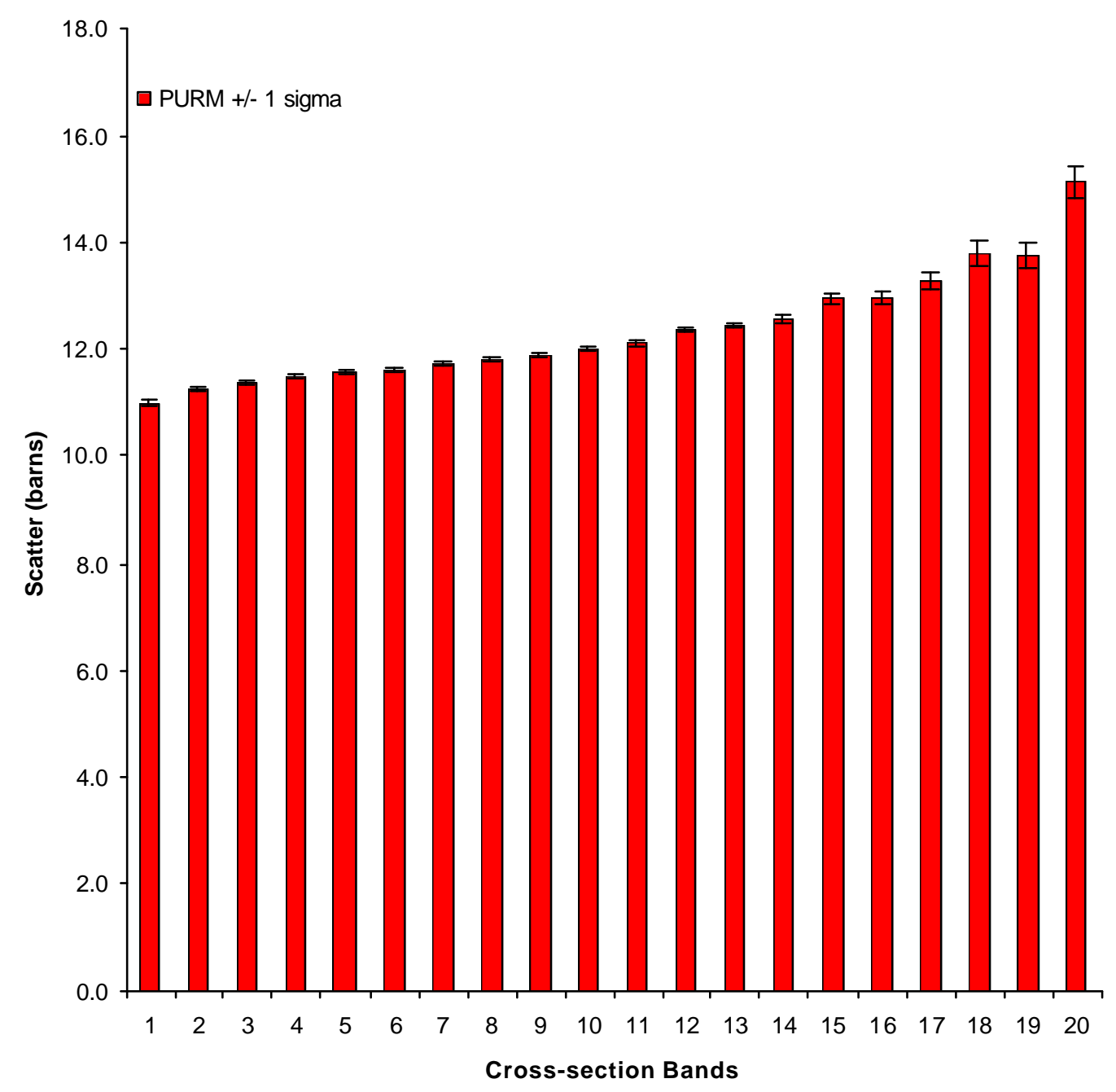

Figure III.9. Calculated scatter cross section as a function of cross-section band for ${ }^{235} \mathrm{U}$ at $2.25 \mathrm{keV}$. 
As noted previously, the NJOY module PURR uses the "ladder" approach to calculate probability tables in the unresolved-resonance region. In order to compare the calculated probability tables between NJOY and PURM, NJOY99.14 was used to calculate probability tables for ${ }^{235} \mathrm{U}$ at $300 \mathrm{~K}$. For the NJOY calculations, NJOY was instructed to generate tables with 20 cross-section bands. Subsequently, the cross-section bands that were generated by NJOY were specified in the PURM input file, and PURM was used to re-calculate the probability tables with the cross-section bands from NJOY. By using the same cross-section bands, a more accurate comparison can be made between the two codes. The probabilities that were calculated by NJOY and PURM at $2.25 \mathrm{keV}$ are presented in Figure III.10. Based on the results in Figure III.10, the PURM-calculated probabilities agree with the NJOY values. Likewise, the NJOY and PURM average total, capture, fission and scatter cross sections are plotted in Figures III.11 through III.14, respectively. For each cross-section band in Figures III.11 through III.14, the PURM cross-section values are in agreement with the NJOY values. Note that similar results are obtained for the remaining 13 probability-table calculations. Based on the verification studies with NJOY, the probability tables as calculated by PURM are suitable for use in nuclear applications.

At this point, extensive studies of the computation times for PURM have not been performed; however, for the ${ }^{235} \mathrm{U}$ test case, the probability tables were calculated using 10,000 histories per table, and PURM requires $\sim 7$ minutes of CPU time for each table on a DEC Alpha AS 500/500 workstation. In comparison with NJOY, the ${ }^{235} \mathrm{U}$ test case was calculated using 10 ladders of resonances per table, and the computational times are $~ 8.6$ seconds per table on the DEC Alpha. Although the computational times for NJOY are much faster for the test case, the two computational approaches are vastly different, and the longer CPU times for PURM are attributed to the number of histories processed, as well as the implementation of the ) ${ }_{3}$-statistics test. Note that NJOY does not use the $)_{3}$-statistics test to evaluate the distribution of resonances sampled from a Wigner distribution. Consequently, NJOY does not have a mechanism for assessing the adequacy of the sampled resonance distribution. In addition, acceptable probability tables may be calculated with PURM using far fewer histories; thereby, reducing the CPU time for each table. However, a parametric study of the number of histories has not been performed for the test case.

Although an advantage in computation time may not be attained with PURM, the procedures in PURM are significantly different from the "ladder" approach used by NJOY. As a result, AMPX provides an independent approach for calculating probability tables for the unresolved-resonance region; thereby, satisfying the AMPX-upgrade objective to facilitate independent processing of ENDF/B data. 


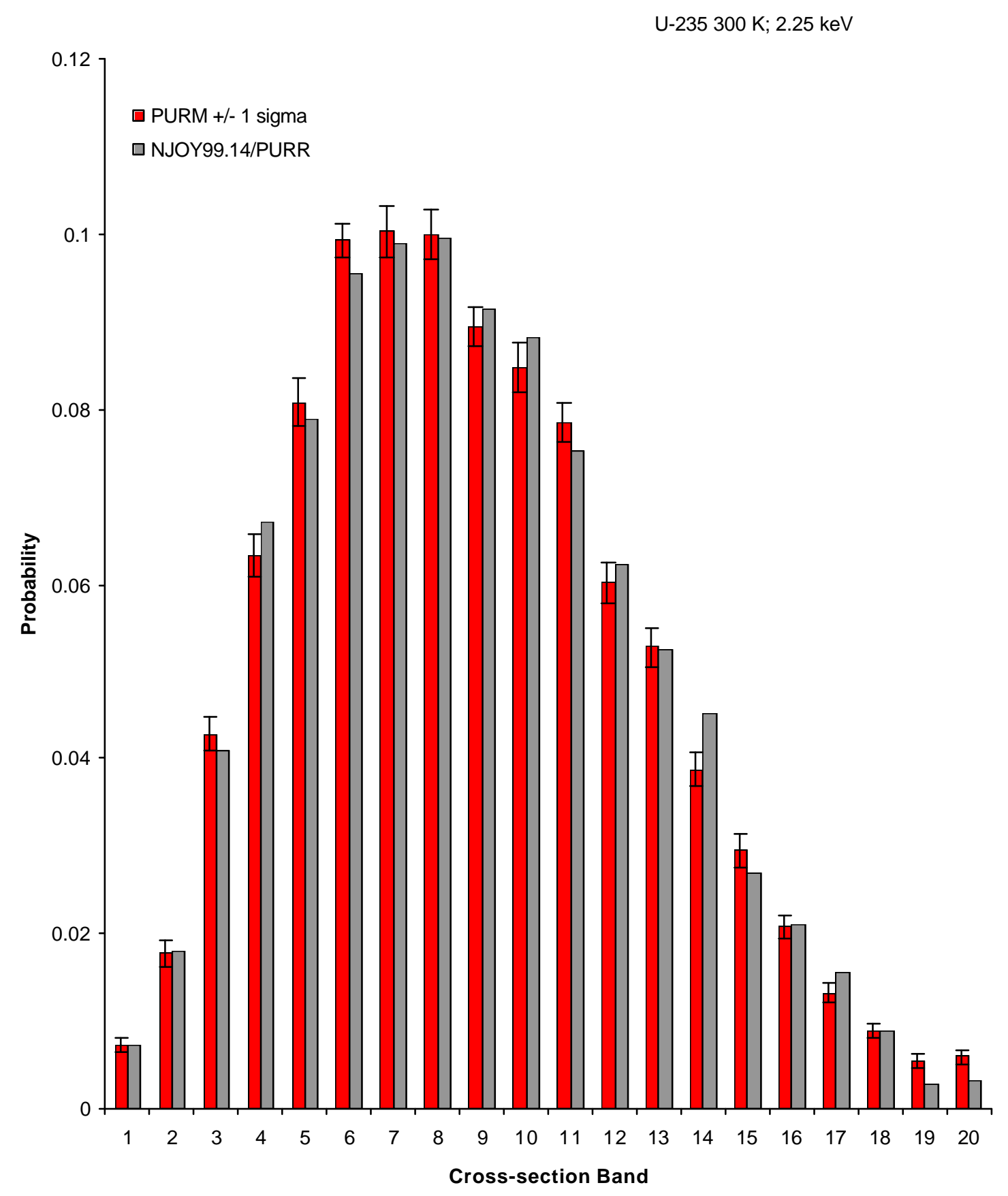

Figure III.10. Probability-table comparison between PURM and NJOY for ${ }^{235} \mathrm{U}$ at $2.25 \mathrm{keV}$. 
U-235 $300 \mathrm{~K} ; 2.25 \mathrm{keV}$

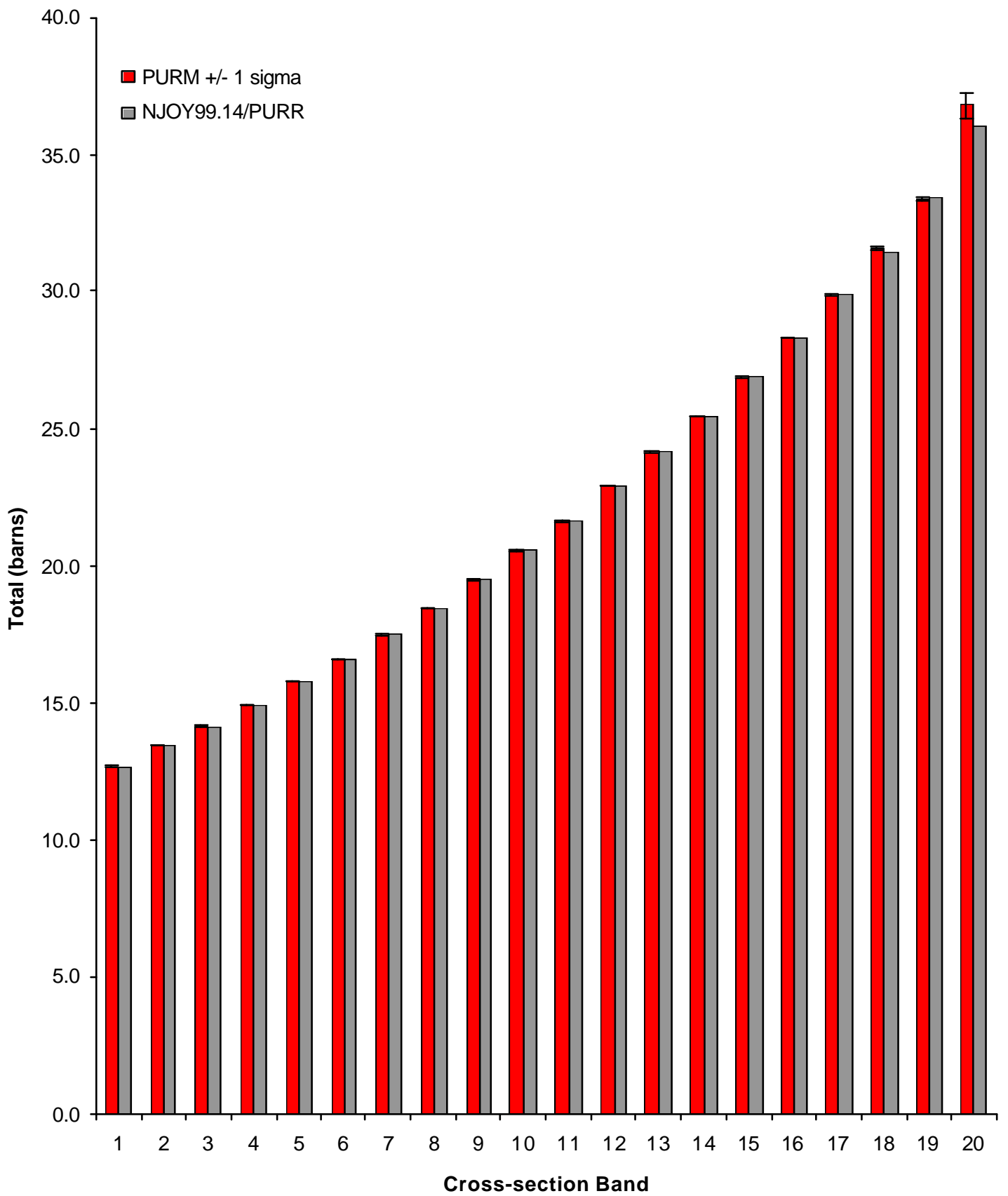

Figure III.11. Total cross-section comparison between PURM and NJOY for ${ }^{235} \mathrm{U}$ at $2.25 \mathrm{keV}$. 


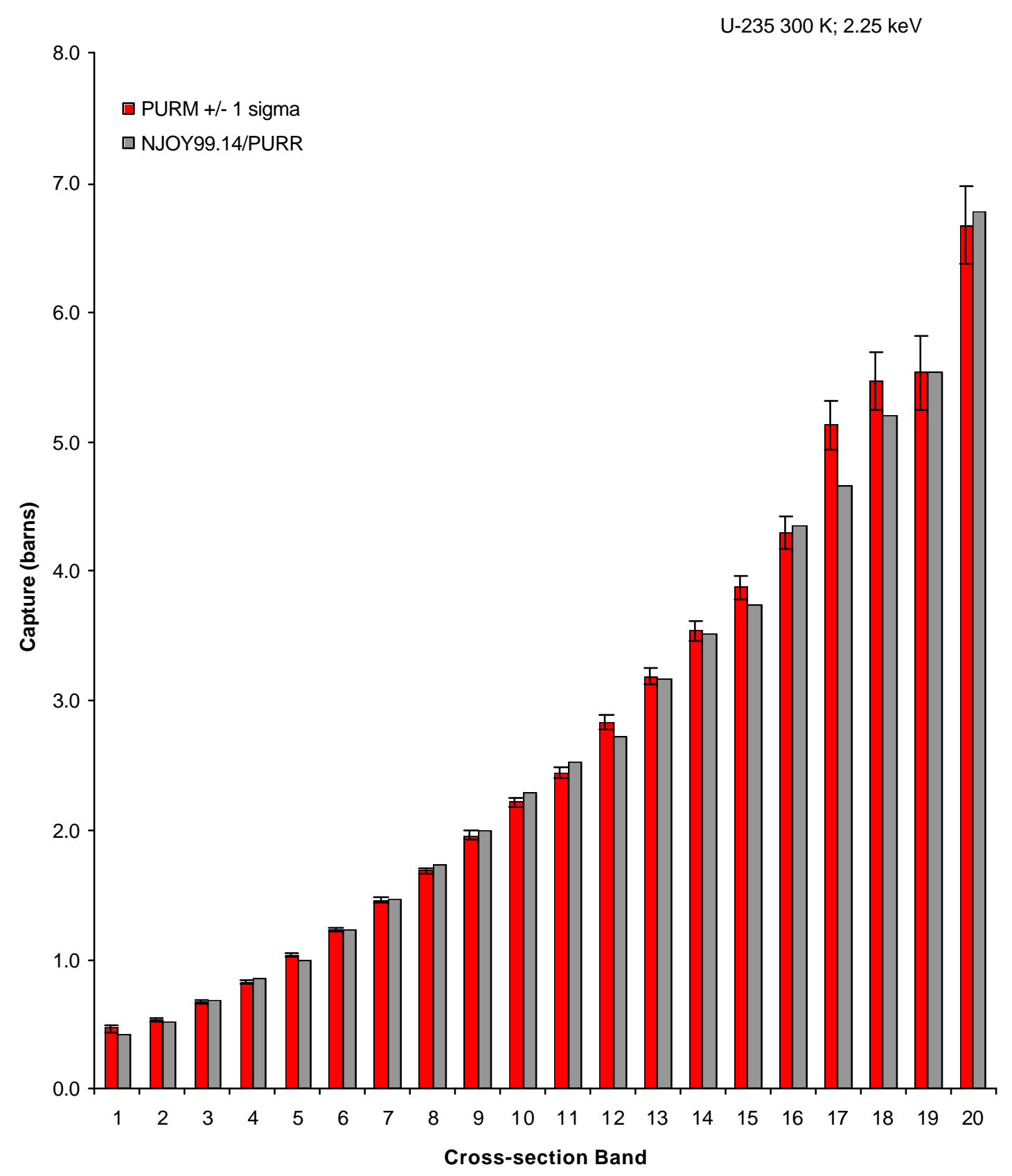

Figure III.12. Capture cross-section comparison between PURM and NJOY for ${ }^{235} \mathrm{U}$ at $2.25 \mathrm{keV}$. 


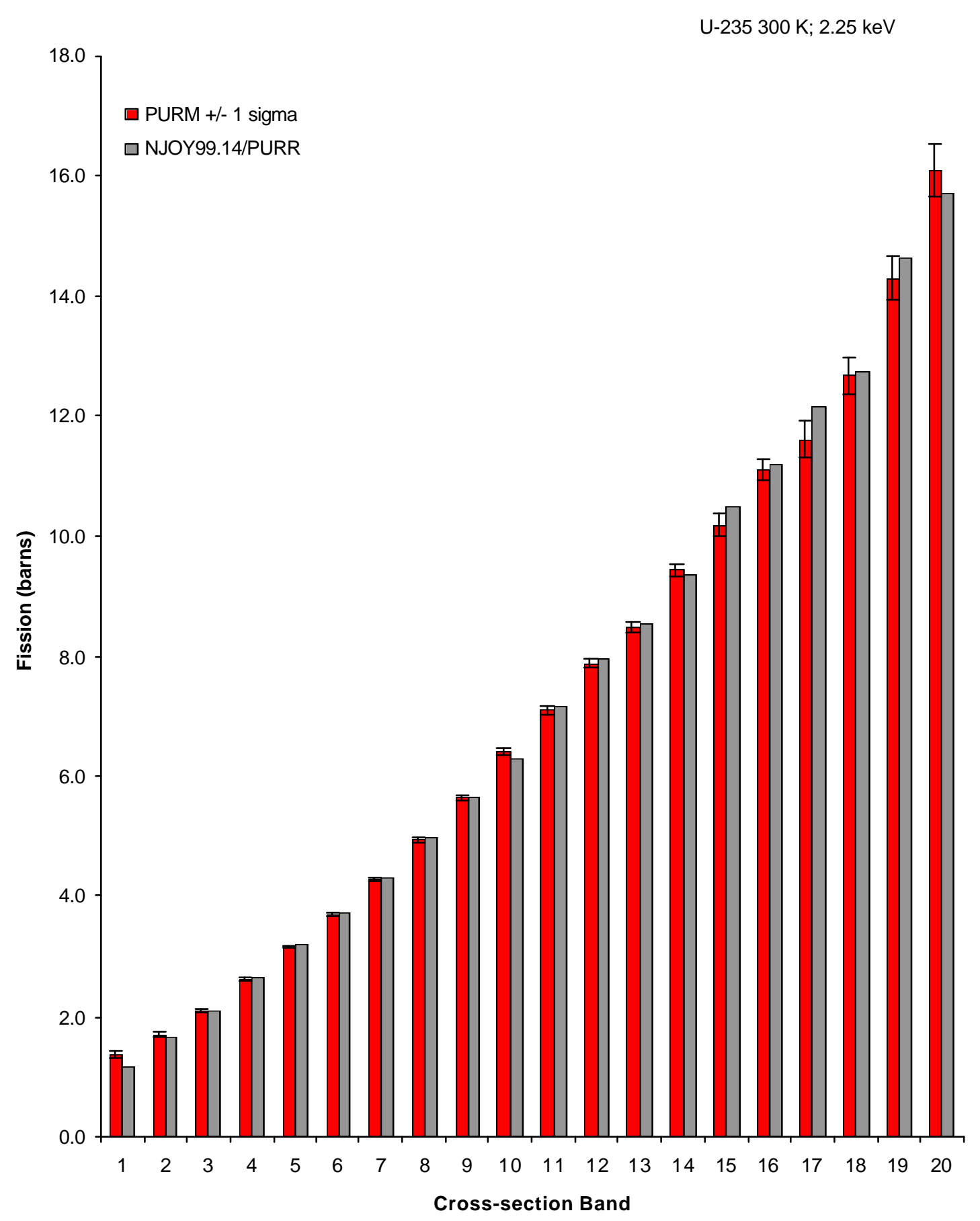

Figure III.13. Fission cross-section comparison between PURM and NJOY for ${ }^{235} \mathrm{U}$ at $2.25 \mathrm{keV}$. 


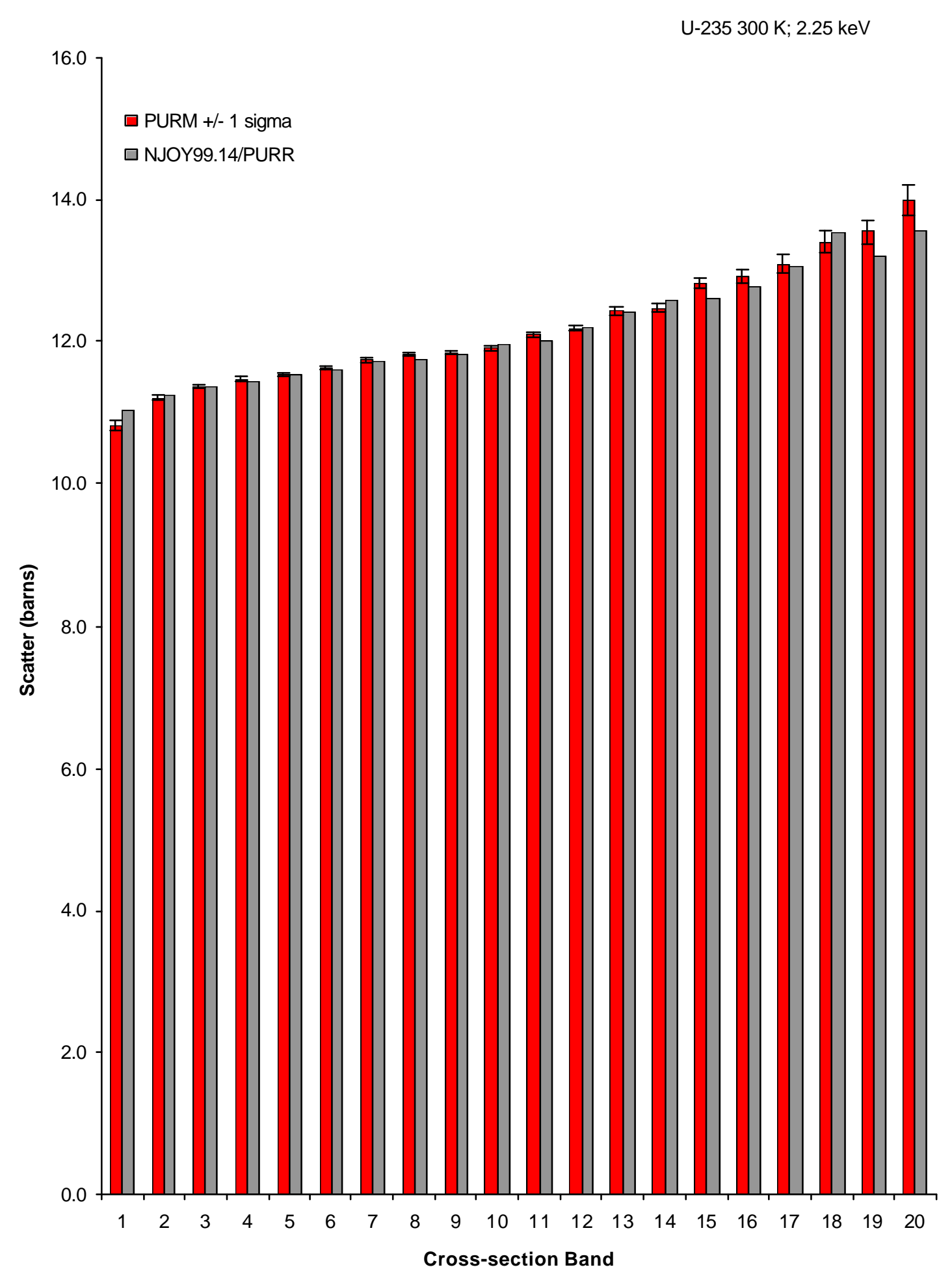

Figure III.14. Scatter cross-section comparison between PURM and NJOY for ${ }^{235} \mathrm{U}$ at $2.25 \mathrm{keV}$. 


\section{SUMMARY}

The DOE Laboratory Project and Cost Proposal for NRC Work (JCN W6479) identifies various subtasks for upgrading the AMPX code system to process ENDF/B-VI data. ${ }^{1}$ The overall objective of the upgrade is to facilitate independent processing of Version 6 formats. Task 8 of the cost proposal addresses the development of the capability to generate probability tables for neutron transport applications in the unresolved-resonance region (URR). In accordance with the reporting requirements for Task 8, this letter report documents development and testing of the capability to generate probability tables for the URR.

A new module for the AMPX code system has been developed to satisfy the objective of Task 8 . The new

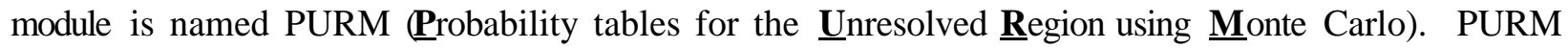
calculates probability tables in the URR using Monte Carlo procedures to sample the resonance spacings and widths. The Monte Carlo procedure used in PURM is based on the methodology in the URR ${ }^{6}$ code that was developed at ORNL in the late 1980s.

PURM samples pairs of resonances surrounding a reference energy for each probability table. The resonance spacings are sampled from a Wigner distribution. PURM uses the ) ${ }_{3}$-statistics test that was developed by Dyson and Mehta ${ }^{7,8}$ to determine the number of resonances to sample for each spin state. For each resonance, PURM samples the resonance widths from a $\mathrm{P}^{2}$-distribution for a specified number of degrees of freedom. Once the resonance parameters are sampled, PURM calculates the total, capture, fission and scatter cross sections at the reference energy using the single-level Breit-Wigner formalism with appropriate treatment for temperature effects.

For the cross-section calculation and corresponding probability-table calculation, PURM performs the Monte Carlo simulation for a user-specified number of batches with a corresponding number of histories or iterations per batch. For each history, PURM calculates the total, capture, fission and scatter cross section at the reference energy, and the corresponding contribution to the probability table is determined for each history. After completing the number of histories for a batch, a batch estimate for the probability for each crosssection band is obtained by dividing the number of tallies for the band by the total number of histories processed. Additional batches are processed until the user-specified number of batches are complete. Once the total number of batches have been processed, the average cross-section values for the entire table should converge to the corresponding infinite-dilution values.

In an effort to establish the capabilities of PURM, probability tables have been calculated for the unresolvedresonance region of ${ }^{235} \mathrm{U}(\mathrm{ENDF} / \mathrm{B}-\mathrm{VI})$. PURM was used to calculate a probability table for each reference energy (i.e., 14 reference points) specified in the ENDF/B evaluation. Each probability table was calculated at $300 \mathrm{~K}$ using 200 batches with 50 histories per batch for a total for 10,000 histories per table. The average cross-section values for the 14 different probability tables were compared with the infinite-dilution values generated by the AMPX module PRUDE. Based on the comparison studies, the average cross-section values for each probability table agree with the infinite-dilution values that were calculated by PRUDE.

As an additional test, the PURM-generated probability tables for ${ }^{235} \mathrm{U}$ were compared with probability tables generated using the NJOY module PURR. For the comparison studies with NJOY, both codes used the same cross-section bands for each table, and the probability tables and cross-section values that were calculated by PURM and NJOY are in agreement. As a result, the verification studies with NJOY establish 
the computational capability for generating probability tables using the new AMPX module PURM. In addition, the probability tables calculated by PURM are suitable for use in nuclear applications. 


\section{REFERENCES}

1. "Development and Applicability of Criticality Safety Software for Licensing Review," DOE Laboratory Project and Cost Proposal for NRC Work, JCN W6479, (September 07, 1999).

2. N. M. Greene, W. E. Ford III, L. M. Petrie, and J. W. Arwood, AMPX-77: A Modular Code System for Generating Coupled Multigroup Neutron-Gamma Cross-Section Libraries from ENDF/B-IV and ENDF/B-V, ORNL/CSD/TM-283, Martin Marietta Energy Systems, Inc., Oak Ridge National Laboratory, October 1992.

3. R. E. MacFarlane and D. W. Muir, NJOY99.0 Code System for Producing Pointwise and Multigroup Neutron and Photon Cross Sections from ENDF/B Data, PSR-480/NJOY99.0, Los Alamos National Laboratory, March 2000.

4. MCNP4C Monte Carlo N-Particle Transport Code System, CCC-700/MCNP4C, Los Alamos National Laboratory, April 2000.

5. L. B. Levitt, "The Probability Table Method for Treating Unresolved neutron Resonances in Monte Carlo Calculations," Nucl. Sci. Eng. 49, 450B457 (1972).

6. L. C. Leal, G. de Saussure and R. B. Perez, URR Computer Code: A Code to Calculate Resonance Neutron Cross-Section Probability Tables, Bondarenko Self-Shielding Factors and Self-Indication Ratios for Fissile and Fertile Nuclides, ORNL/TM-11297, Martin Marietta Energy Systems, Inc, Oak Ridge National Laboratory, August 1989.

7. F. J. Dyson and M. L. Mehta, "Statisical Theory of the Energy Levels of Complex Systems," J. Math. Phys. 4, 701 (May 1963).

8. L. C. Leal and N. M. Larson, SAMDIST: A Computer Code for Calculating Statistical Distributions for R-Matrix Resonance Parameters, ORNL/TM-13092, Lockheed Martin Energy Research Corporation, Oak Ridge National Laboratory, September 1995.

9. C. E. Porter and R. G. Thomas, "Fluctuations of Nuclear Reaction Widths," Phys. Rev. 104, 483B491 (October 1956).

10. "ENDF-102 Data Formats and Procedures for the Evaluated Nuclear Data File ENDF-6," BNL-NCS44945, Rev. 10/91 (ENDF/B-VI), Brookhaven National Laboratory, October 1991.

11. Lyman Ott, An Introduction to Statistical Methods and Data Analysis, Third Edition, PWS-KENT Publishing Company, Boston, MA, 1988.

12. SCALE: A Modular Code System for Performing Standardized Computer Analyses for Licensing Evaluation, NUREG/CR-0200, Rev. 6 (ORNL/NUREG/CSD-2R6), Vols I, II, and III, May 2000. Available form Radiation Safety Information Computational Center at the Oak Ridge National Laboratory as CCC-545. 
ORNL/NRC/LTR-00/11

\section{INTERNAL DISTRIBUTION}

1. W. C. Carter, 6011, MS-6370

2. M. E. Dunn, 6011, MS-6370

3. N. M. Greene, 6011, MS-6370

4. D. T. Ingersoll, 6025, MS-6363

5. M. A. Kuliasha, 6025, MS-6435

6. L. C. Leal, 6011, MS-6370

7. C. V. Parks, 6011 , MS-6370
8. L. M. Petrie, 6011, MS-6370

9. R. T. Primm III, 6025, MS-6363

10. C. E. Pugh, 9201-3, MS-8063

11. R. W. Roussin, 6025, MS-6362

12. J. J. Simpson, 9201-3, MS-8063

13. R. M. Westfall, 6011, MS-6370

14. Laboratory Records, 4500 N, MS-6285

\section{EXTERNAL DISTRIBUTION}

15. D. E. Carlson, NMSS/SFPO/TRD, U.S. Nuclear Regulatory Commission, MS O13-D13, Washington, DC 20555-0001

16B20. D. D. Ebert, RES/DSARE/SMSAB, U.S. Nuclear Regulatory Commission, MS T10-K8, Washington, DC 20555-0001 
